OPEN ACCESS

Edited by:

Christiane Pienna Soares, São Paulo State University, Brazil

Reviewed by: Paul Dent,

Virginia Commonwealth University, United States

Mariusz Lukasz Hartman, Medical University of Lodz, Poland Alejandro Villagra, The George Washington University, United States

Abdullah Al Emran, University of Sydney, Australia Heidi Olzscha,

Martin Luther University of Halle-Wittenberg, Germany

*Correspondence: Dooil Jeoung jeoungd@kangwon.ac.kr

Specialty section:

This article was submitted to Epigenomics and Epigenetics, a section of the journal Frontiers in Cell and Developmental

Biology

Received: 03 April 2020

Accepted: 22 May 2020

Published: 17 June 2020

Citation:

Yeon M, Kim Y, Jung HS and Jeoung D (2020) Histone Deacetylase Inhibitors to Overcome Resistance to Targeted and Immuno Therapy

in Metastatic Melanoma.

Front. Cell Dev. Biol. 8:486.

doi: 10.3389/fcell.2020.00486

\section{Histone Deacetylase Inhibitors to Overcome Resistance to Targeted and Immuno Therapy in Metastatic Melanoma}

\author{
Minjeong Yeon ${ }^{1}$, Youngmi Kim², Hyun Suk Jung ${ }^{1}$ and Dooil Jeoung ${ }^{1 *}$ \\ ${ }^{1}$ Department of Biochemistry, College of Natural Sciences, Kangwon National University, Chunchon, South Korea, ${ }^{2}$ Institute \\ of New Frontier Research, College of Medicine, Hallym University, Chunchon, South Korea
}

Therapies that target oncogenes and immune checkpoint molecules constitute a major group of treatments for metastatic melanoma. A mutation in BRAF (BRAF V600E) affects various signaling pathways, including mitogen activated protein kinase (MAPK) and PI3K/AKT/mammalian target of rapamycin (mTOR) in melanoma. Target-specific agents, such as MAPK inhibitors improve progression-free survival. However, BRAFV600E mutant melanomas treated with BRAF kinase inhibitors develop resistance. Immune checkpoint molecules, such as programmed death-1 (PD-1) and programmed death ligand-1(PDL1), induce immune evasion of cancer cells. MAPK inhibitor resistance results from the increased expression of PD-L1. Immune checkpoint inhibitors, such as anti-PDL1 or anti-PD-1, are main players in immune therapies designed to target metastatic melanoma. However, melanoma patients show low response rate and resistance to these inhibitors develops within 6-8 months of treatment. Epigenetic reprogramming, such as DNA methylaion and histone modification, regulates the expression of genes involved in cellular proliferation, immune checkpoints and the response to anti-cancer drugs. Histone deacetylases (HDACs) remove acetyl groups from histone and nonhistone proteins and act as transcriptional repressors. HDACs are often dysregulated in melanomas, and regulate MAPK signaling, cancer progression, and responses to various anti-cancer drugs. HDACs have been shown to regulate the expression of PD1/PD-L1 and genes involved in immune evasion. These reports make HDACs ideal targets for the development of anti-melanoma therapeutics. We review the mechanisms of resistance to anti-melanoma therapies, including MAPK inhibitors and immune checkpoint inhibitors. We address the effects of HDAC inhibitors on the response to MAPK inhibitors and immune checkpoint inhibitors in melanoma. In addition, we discuss current progress in anti-melanoma therapies involving a combination of HDAC inhibitors, immune checkpoint inhibitors, and MAPK inhibitors.

Keywords: anti-cancer drug resistance, HDACs, immune checkpoint, MAPK, melanoma 


\section{INTRODUCTION}

Melanoma arises from melanocytes in the skin or mucosa (Chodurek et al., 2014). Metastatic melanoma accounts for about $1-2 \%$ of skin cancers (Jiang et al., 2017). However, it is responsible for $90 \%$ of all mortality in skin cancer patients. Over the past decade, a better understanding of the molecular basis of melanoma has led to the development of anti-cancer drugs that target molecular signaling pathways that are activated in malignant metastatic melanoma.

Since 2011, several chemical inhibitors that target molecular signaling pathways have been approved by the FDA. These chemical inhibitors include vemurafenib, dabrafenib, trametinib, encorafenib, binimetinib, and cobimetinib. These anti-cancer drugs inhibit MAPK (BRAF/MEK/ERK) signaling (Pedini et al., 2019; Yarchoan et al., 2019; Ascierto et al., 2020a,b; Krayem et al., 2020). Vemurafenib improves overall survival ( $84 \%$ vs. $64 \%$ ) and response rate ( $48 \%$ vs. $5 \%$ ) compared with standard anti-cancer drug treatment, such as dacarbazine, in melanoma patients with the $B R A F^{V 600 E}$ mutation (Chapman et al., 2011). A combination of dabrafenib and trametinib improved overall survival at 12 months compared with vemurafenib treatment ( $72 \%$ vs. $65 \%$ ) in a phase 3 clinical trial of $B R A F^{V 600 E}$ mutant melanoma patients (Robert et al., 2015). However, innate and acquired resistance to these anti-cancer drugs is a serious problem.

The tumor microenvironment plays a major role in the proliferation of melanoma cells and anti-cancer drug resistance (Guo et al., 2020). The tumor microenvironment consists of cancer cells, endothelial cells, fibroblasts, and innate and adaptive immune cells. Cancer cells interact with immune cells such as natural killer (NK) cells, macrophages (M1/M2), myeloid-derived suppressor cells (MDSCs), and cytolytic T lymphocytes (CTLs). Cancer cells can evade the antitumor response of CTLs (Freeman et al., 2019). Immune checkpoint molecules, such as PD-1 and PD-L1, regulate the interactions between cancer cells and immune cells. The interaction between PD-1 and PD-L1 leads to immune evasion of cancer cells (Hei et al., 2020). Immunotherapy aims to suppress immune evasion (tumor tolerance) by targeting the interactions between cancer cells and immune cells.

Over the last decade, immune checkpoint inhibitors (nivolumab and pembrolizumab) targeting PD-1/PD-L1 interactions have been approved by the FDA. In a clinical trial of elderly patients ( $>75$ years old) with metastatic melanoma, nivolumab (anti-PD-1 antibody) showed clinical benefits and was well tolerated (Ridolfi et al., 2020). Pembrolizumab, an antiPD-1 antibody, improved progression-free survival compared to BRAF inhibitors and PD-L1 inhibitors in clinical trial of stage III melanomas (Lorenzi et al., 2019). A phase Ib trial of avelumab, an anti-PD-L1 antibody, in 51 patients with stage IV unresectable melanoma showed an objective response rate (ORR) of $21.6 \%$ (Keilholz et al., 2019). Thirty-nine patients experienced side effects, including infusion-related reactions, fatigue, and chills (Keilholz et al., 2019).

Histone acetylation/deacetylation plays a critical role in the expression of genes involved in immune evasion of cancer cells (Knox et al., 2019). Histone modification is closely associated with cancer progression (Halasa et al., 2019). High expression levels of several HDACs have been associated with poor survival in cancer patients (Dembla et al., 2017). Thus, HDACs may regulate expression of $\mathrm{PD}-1$ and $\mathrm{PD}-\mathrm{L} 1$. These reports suggest that HDACs may be targets for the development of antimelanoma therapies.

Herein, we review the roles of signaling pathways and immune checkpoint molecules in melanoma progression and anti-cancer drug resistance. We address the roles of HDACs in the regulation of oncogenic signaling pathways and immune evasion by cancer cells. We also discuss current progress in combination therapies that employ histone deacetylases inhibitors, targeted treatments, and immune therapy for treatment of malignant melanoma.

\section{THE MECHANISMS OF ANTI-CANCER DRUG RESISTANCE IN MELANOMA}

Melanoma is a common and potentially lethal type of skin cancer. Almost half of all cutaneous melanomas have the $B R A F^{V 600 E}$ gene mutation that results in activation of MAPK signaling (Feng T. et al., 2019; Rossi et al., 2019; Woo et al., 2019). $B R A F^{V 600 E}$ mutant metastatic melanomas display activation of both MAPK-dependent and -independent signaling pathways for survival under MAPK inhibitor treatment in a PDX mouse model (Feng T. et al., 2019). BRAF/MEK inhibitors have some clinical benefits. However, melanoma patients develop resistance to these inhibitors within 6-8 months (Roskoski, 2018; Fujimura et al., 2019).

Anti-cancer drug resistance can be classified into innate and acquired resistance. Innate resistance exists even before treatment while acquired resistance develops after treatment. Innate anti-cancer drug resistance is closely related to inherent gene mutations (Shinohara et al., 2019), drug efflux (Xiao et al., 2018, Figure 1A), and selection of cancer stem cells upon treatment (Green et al., 2019, Figure 1B). DNA damage repair (Figure 1A), phenotypic switching, epigenetic reprogramming (Figure 1C), enrichment of slow cycling cells (Figure 1C), and reactivation of molecular signaling pathways also play critical roles in anti-cancer drug resistance. High level of ABCB5 (ATP-binding cassette transporter, subfamily B, member 5) is responsible for resistance to the $B R A F$ inhibitor vemurafenib (Xiao et al., 2018). Enhanced DNA damage repair by NF- $\kappa$ B confers resistance to chemotherapy (Li et al., 2017).

Anti-cancer drug resistance is associated with the presence of induced drug-tolerant cells (Kim et al., 2010, 2015; Al Emran et al., 2018). These induced drug-tolerant cells resulting from exposure to chemotherapy display histone lysine modifications, which are characteristic of epigenetic reprogramming (Al Emran et al., 2018). Exposure to vemurafenib enriches slow cycling melanoma cells expressing H3K4-demethylase JARID1B (Roesch et al., 2013). Inhibition of mitochondrial function enhances sensitivity to vemurafenib by decreasing the expression of JARID1B (Roesch et al., 2013). Rapidly proliferating cancer cells, but not slow cycling cells, are the main subjects of targeted therapy. Slow cycling cancer cells are enriched by anti-cancer drugs and confer resistance by activating various signaling pathways, including the WNT5A and EGFR pathways 


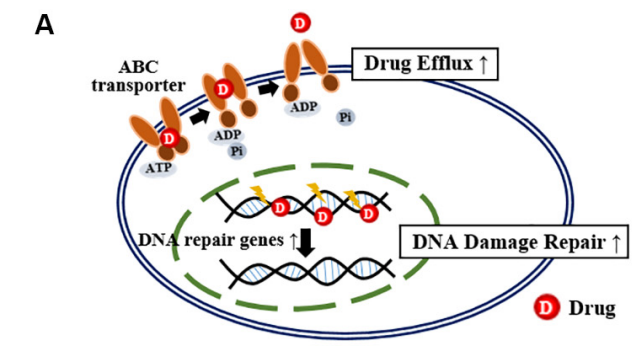

B
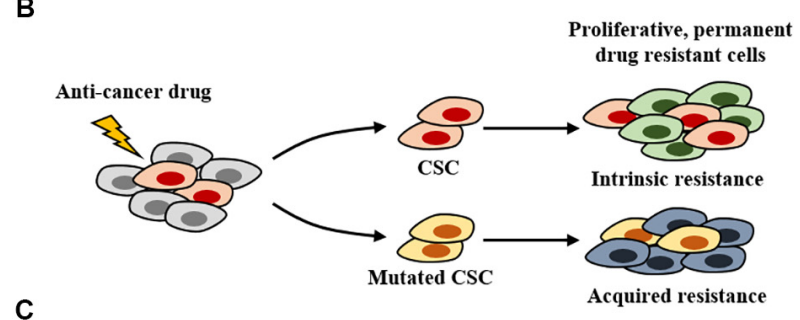

C

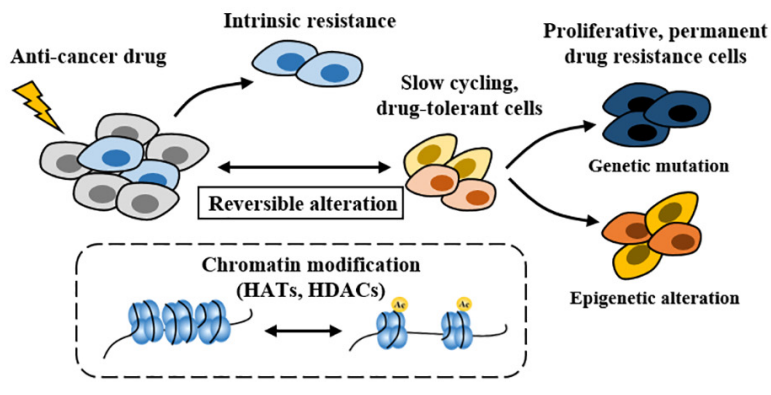

D

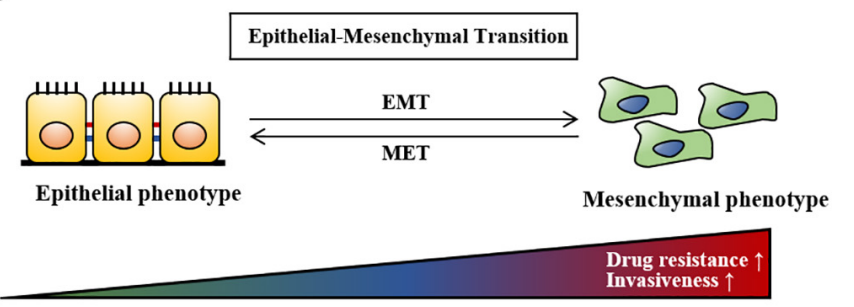

E

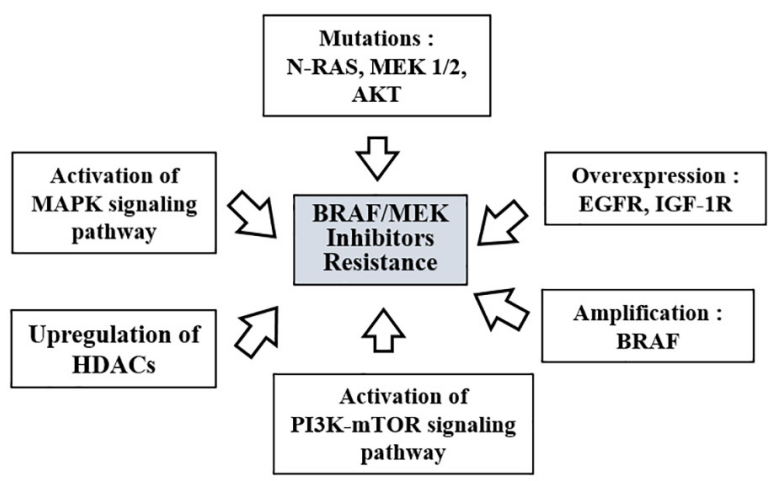

FIGURE 1 | The mechanisms of anti-cancer drug resistance. (A) Drug efflux by ABC transporter activity, drug inactivation, and alterations in drug targets leads to anti-cancer drug resistance. Increased DNA damage repair also leads to anti-cancer drug resistance. (B) Cancer stem cells survive anti-cancer drug treatment. Mutations (point mutations, gene amplifications etc.) in these cancer stem cells lead to anti-cancer drug resistant phenotypes. Cancer stem cells that survive anti-cancer drug treatment proliferates and lead to antiOcancer drug resistance (intrinsic resistance). CSC denotes cancer stem cell. (C) Slow-cycling drug-tolerant cells are selected on treatment by reversible epigenetic reprogramming. Further epigenetic reprogramming give rise to re-proliferating drug-resistant cells. Genetic mutation in slow-cycling drug-tolerant cells also give rise to permanent drug-resistant cells. HATs denote histone acetyl transferases. (D) Mesenchymal transition is closely related to increased drug resistance and invasiveness. MET denotes mesenchymal-epithelial transition. (E) Repeated exposure to BRAF inhibitors spurs resistance. BRAF inhibitor resistance develops from gene amplification, gene overexpression, genetic mutations, activation of signaling pathways, and upregulation of HDACs.

(Ahn et al., 2017). Figure 1 shows the mechanisms of anti-cancer drugs resistance. Tumor heterogeneity and plasticity (phenotypic switching) are responsible for resistance to various anti-cancer drugs (Su et al., 2019, Figure 1D). Tumor heterogeneity includes cell type heterogeneity and genetic heterogeneity. These characteristics make it almost impossible to rely on a single therapy for cancer treatment. Melanoma cells switch between differentiated (proliferative) and de-differentiated (invasive) states during metastatic progression. Phenotypic switching toward the de-differentiated state leads to resistance to BRAF and MEK inhibitors (Granados et al., 2020). BRAF inhibitor treatment induces mesenchymal transition, which leads to BRAF inhibitor resistance (Su et al., 2019).

$\mathrm{BRAF/MEK}$ inhibitor resistance in melanoma is associated with increased expression of EGFR (Ahn et al., 2017; Dratkiewicz et al., 2019). Resistance to BRAF inhibitors (dabrafenib or vemurafenib) results from $B R A F$ amplification, $A K T$ mutation, $N$-RAS mutation, $M E K 1 / M E K 2$ mutation, and high level of insulin like growth factor-1 receptor (IGF-1R) in
$B R A F^{V 600 E}$ mutant melanomas (Rizos et al., 2014, Figure 1E). AKT1(Q79K) mutation also confers resistance to BRAF inhibitors (vemurafenib or dabrafenib) via amplification of PI3K-AKT signaling (Shi et al., 2014). Resistance to BRAF inhibitors (vemurafenib or dabrafenib) results from alterations in MAPK pathway, such as MAP2K2, and melanocyte inducing transcription factor (MITF) (Van Allen et al., 2014). Melanoma cells can adapt to the drugs through phenotypic switching (plasticity), which results in resistance to targeted therapies such as BRAF and MEK inhibitors (Richard et al., 2016; Hartman et al., 2020). MITF, a regulator of melanoma cell plasticity, shows heterogeneous expression in cancer cell subpopulations (Vachtenheim and Ondrusova, 2015). Low expression of MITF expression is associated with invasion while high MITF expression favors cellular proliferation (Vachtenheim and Ondrusova, 2015). MITF regulates invasion of melanoma cells through negative feedback loop with Notch signaling (Golan and Levy, 2019). Therapy-resistant melanoma show low expression of MITF (Ahmed and Haass, 2018). High MITF level 
is found in more than $20 \%$ of melanomas following MAPK inhibitor treatment (Van Allen et al., 2014; Smith et al., 2016). MAPK inhibition leads to increased expression of MITF, which counteracts the effect of the MAPK inhibitor (Smith et al., 2019). Reactivation of MAPK signaling leads to activation of the PI3K-mTOR signaling pathway, which confers resistance to the BRAF inhibitors vemurafenib and dabrafenib (Welsh et al., 2016). Resistance to the BRAF inhibitor SB-590885 results from activation of IGF-1R/PI3K signaling (Villanueva et al., 2010). Resistance to PLX4720, an inhibitor of BRAF, results from upregulation of HDACs based on the fact that pan-HDAC inhibitors overcome resistance to PLX4720 (Lai et al., 2012). Trametinib-resistant melanoma cells show increased expression of HDACs 2/5/6/10/11 (Booth et al., 2017). A combination of vemurafenib and the MEK inhibitor trametinib increases the expression of HDAC8 in melanoma cells (Emmons et al., 2019). This increased expression of HDAC8 leads to the activation of MAPK signaling via receptor tyrosine kinases, such as EGFR and proto-oncogene MET, which confers resistance to the combination of BRAF inhibitor and MEK inhibitor (Emmons et al., 2019). It is therefore probable that HDAC8 is responsible for acquired resistance to the BRAF and MEK inhibitors. Figure 1E shows the mechanisms associated with resistance to BRAF inhibitors.

These reports suggest that targeting signaling pathways and/or HDACs may overcome resistance to BRAF inhibitors. Cancers are generally heterogeneous and multiclonal. An individual cancer reflects differences in mutations of various genes. Therefore, a combination of anti-cancer drugs is employed as anti-cancer therapy. Aberrant activation of the MAPK pathway is a major feature in most cases of melanoma (Dikshit et al., 2018). A combination of BRAF and MEK inhibitors has been employed for the treatment of metastatic melanomas harboring the $B R A F^{V 600 E}$ mutation. The anti-tumor effects of these BRAF inhibitors are enhanced by co-administration of MEK inhibitors (Dummer et al., 2018). The combination of dabrafenib and trametinib results in stronger inhibition of activity of specific tyrosine kinases than does treatment with dabrafenib alone (Krayem et al., 2020). The combination of a BRAF inhibitor (dabrafenib) and a MEK inhibitor (trametinib) increases the expression of KIT, a tumor suppressor, and also induces alterations in CCND1, RB1, and MET in patients with $B R A F^{V 600 E}$ metastatic melanoma (Louveau et al., 2019). The combination of cobimetinib (MEK inhibitor) and vemurafenib (BRAF inhibitor) improved progression-free survival compared to vemurafenib monotherapy in patients with $B R A F^{V 600}$ mutant metastatic melanoma in a phase 3 clinical trial (12.3 months vs. 7.2 months; Ascierto et al., 2016). In a phase III clinical of patients with advanced melanoma harboring the $B R A F^{V 600 E}$ mutation, the combination of BRAF and MEK inhibitors (dabrafenib plus trametinib) increased the 3-year relapse-free survival rate compared to placebo treatment (58\% vs. 39\%) (Long et al., 2017).

Blockade of MAPK signaling pathway with BRAF and MEK inhibitors induces favorable responses, but most patients eventually develop resistance to these inhibitors. Melanoma patients harboring the $B R A F^{V 600 E}$ mutation display primary resistance. Prolonged treatment with BRAF/MEK inhibitors induces acquired resistance (Atzori et al., 2020). These reports suggest that targeting molecular reprogramming induced by $\mathrm{BRAF/MEK}$ inhibitors is necessary to treat melanomas.

\section{THE ROLES OF HDACs in MELANOMA GROWTH AND ANTI-CANCER DRUG RESISTANCE}

HDACs deacetylate the lysine residues of histones that prevent transcription factor access (Guan et al., 2020). The HDAC family can be subdivided into four categories: Class I HDACs comprise HDAC 1, HDAC 2, HDAC 3, and HDAC 8, which are expressed in most tissues and localized in the nucleus. Class IIa HDACs (HDAC 4, HDAC 5, HDAC 7 and HDAC 9) are present in the nucleus and cytoplasm. Class IIb HDACs (HDAC 6 and HDAC 10) are expressed in a tissue-specific manner and localized in the cytoplasm. HDAC 11, the class IV HDAC, is present in the nucleus (Sahakian et al., 2015). Classes I, II, and IV HDACs require $\mathrm{Zn}^{2+}$ in their catalytic site, whereas class III HDACs require $\mathrm{NAD}^{+}$for their deacetylase activity (Figure 2). Class III HDACs comprises seven sirtuin proteins (SIR1-7) and are homologous with the yeast protein SIR2. Inhibitors targeting classes I, II, and IV HDACs bind to the catalytic core of the $\mathrm{Zn}^{2+}$ binding site. Figure 2 shows classification, functional domains, and inhibitors of HDACs.

Chromatin state changes regulated by HDACs are closely associated with melanoma progression (Al Emran et al., 2018; Emran et al., 2019; Luo et al., 2020). Resistance to BRAF inhibitor results from increased expression of HDACs (Booth et al., 2017; Emmons et al., 2019). Downregulation of peroxisome proliferator-activated receptor $\gamma$ coactivator $1-\alpha \quad(\mathrm{PGC} 1 \alpha)$ expression by $\mathrm{H} 3 \mathrm{~K} 27 \mathrm{me} 3$ suppresses melanoma cell invasion (Luo et al., 2020). Aberrant expression, dysregulation of HDACs or imbalances between HDACs and histone acetyltransferases (HATs) promotes cancer progression (Krumm et al., 2016). Induced drug-tolerant melanoma cells show increased level of H3K9me3 and loss of H3K4me3/H3K27me3 (Al Emran et al., 2018). The loss of $\mathrm{H} 3 \mathrm{~K} 4 \mathrm{me} 3$ in combination with increased DNA methylation of tumor suppressor genes leads to acquired anticancer drug resistance (Al Emran et al., 2018). The increased levels of $\mathrm{H} 3 \mathrm{~K} 18 \mathrm{ac}$ and $\mathrm{H} 3 \mathrm{~K} 27 \mathrm{ac}$ are responsible for multidrug resistance in renal cell carcinoma cells (Zhu et al., 2019). It is reasonable to conclude that an epigenetic regulator, such as HDACs/HATs, can regulate cancer cell growth and the responses to anti-cancer drugs.

HDACs regulate the expression levels of genes involved in melanoma cell proliferation (Kim et al., 2015; Chen et al., 2019). Malignant melanoma cells display high levels of $\mathrm{HDAC} 1 / 2 / 3$ compared to normal cells (Krumm et al., 2016). High expression of HDAC1 is seen in prostate cancers and breast cancers (Gameiro et al., 2016; Tang et al., 2017). Apicidin, an inhibitor of HDAC2 and HDAC3, decreases the expression of Notch1 by decreasing the level of H3Kac27 (Ferrante et al., 2020). Notch 1 signaling suppresses anti-tumor immunity by increasing the expression of TGF- $\beta 1$ (Yang et al., 2018). Increased expression of HDAC2 is seen in human melanoma cells $\left(\right.$ Malme $3 \mathrm{M}^{\mathrm{R}}$ ) 


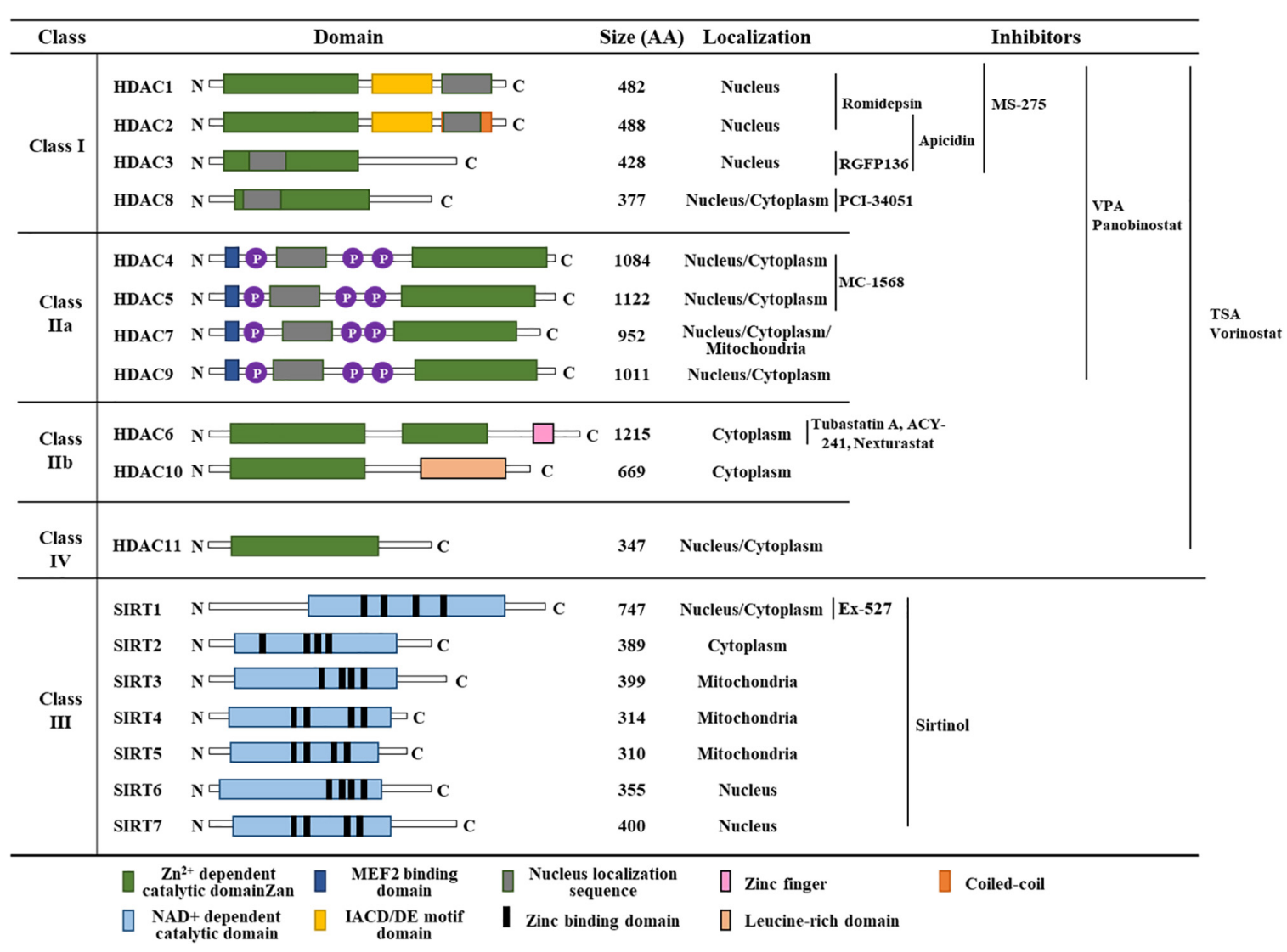

FIGURE 2 | Classification of HDACs, functional domains, and HDAC inhibitors. TSA denotes trichostatin A. AA denotes amino acids.

that have been made resistant to various anti-cancer drugs by repeated exposure to the anti-cancer drug celastrol (Kim et al., 2010). Downregulation of HDAC4 leads to apoptosis of head and neck cancer cells (Lee et al., 2018). HDAC5 promotes invasion of hepatocellular carcinoma cells by increasing the expression of hypoxia-inducible factor-1 (Ye et al., 2017). HDAC5 enhances the metastatic potential of neuroblastoma cells by decreasing the expression of CD9 via hypermethylation (Fabian et al., 2016). The hypermethylation of miR-589 promotes mesenchymal transition by upregulation of HDAC5 in non-small cell lung cancer cells (Liu et al., 2017). HDAC6, which is highly expressed in various melanoma cells, is necessary for invasion and metastasis of melanoma cells (Liu et al., 2016). HDAC6 deacetylates Lys-72 of extracellular signal-regulated kinase 1 (ERK1) and promotes ERK1 activity (Wu et al., 2018). HDAC6 binds to Tyrosine-protein phosphatase non-receptor type 1 (PTPN1), activates extracellular signal-regulated kinase $1 / 2$ (ERK1/2), inhibits apoptosis, and promotes melanoma cell proliferation (Liu et al., 2018). HDAC7 regulates the level of acetyl-H3K27 and is necessary for maintaining cancer stem cells (Caslini et al., 2019). HDAC9 is highly expressed in most gastric cancer cells and plays on oncogenic role (Xiong et al., 2019). HDAC10 promotes angiogenesis by activating ERK1/2 phosphorylation (Duan et al., 2017). The class I and II HDAC inhibitor trichostatin A (TSA) decreases the expression of the genes involved in driving the extracellular signal-regulated kinase (ERK) $1 / 2$ oncogenic pathway (Mazzio and Soliman, 2018).

Valproic acid (VPA), an inhibitor of HDACs, binds to HDAC2 and enhances sensitivity to anti-cancer drugs (Kalal et al., 2019). HDAC2 binds to the cancer/testis antigens, such as CAGE, and leads to multi-drug resistance by decreasing p53 expression in melanoma cells (Kim et al., 2010, Figure 3A). HDAC5 confers resistance to tamoxifen by inducing deacetylation and nuclear localization of SOX9 (Xue et al., 2019). HDAC6 binds to tubulin $\beta 3$ and confers resistance to anti-cancer drugs in Malme $3 \mathrm{M}^{\mathrm{R}}$ cells (Kim et al., 2015). Malme $3 \mathrm{M}^{\mathrm{R}}$ cells show low expression level of HDAC3 compared to parental anti-cancer drug sensitive melanoma cells (Malme3M) (Kim et al., 2014). Overexpression of HDAC3 enhances sensitivity to anti-cancer drugs by disrupting the interaction between HDAC6 and tubulin $\beta 3$ (Kim et al., 2015, Figure 3B). HDAC3 decreases the expression of tubulin $\beta 3$ by binding to its promoter sequences (Kim et al., 2015). HDAC3 suppresses the angiogenic potential of Malme $3 \mathrm{M}^{\mathrm{R}}$ cells by decreasing the expression levels of plasminogen activator inhibitor-1 (PAI-1) and vascular endothelial growth factor (VEGF) (Park et al., 2014, Figure 3B). HDAC3 forms a negative feedback loop with miR-326 and enhances sensitivity to anti-cancer drugs in vitro and in vivo (Kim et al., 2014). Thus, increasing HDAC3 expression may overcome resistance to 


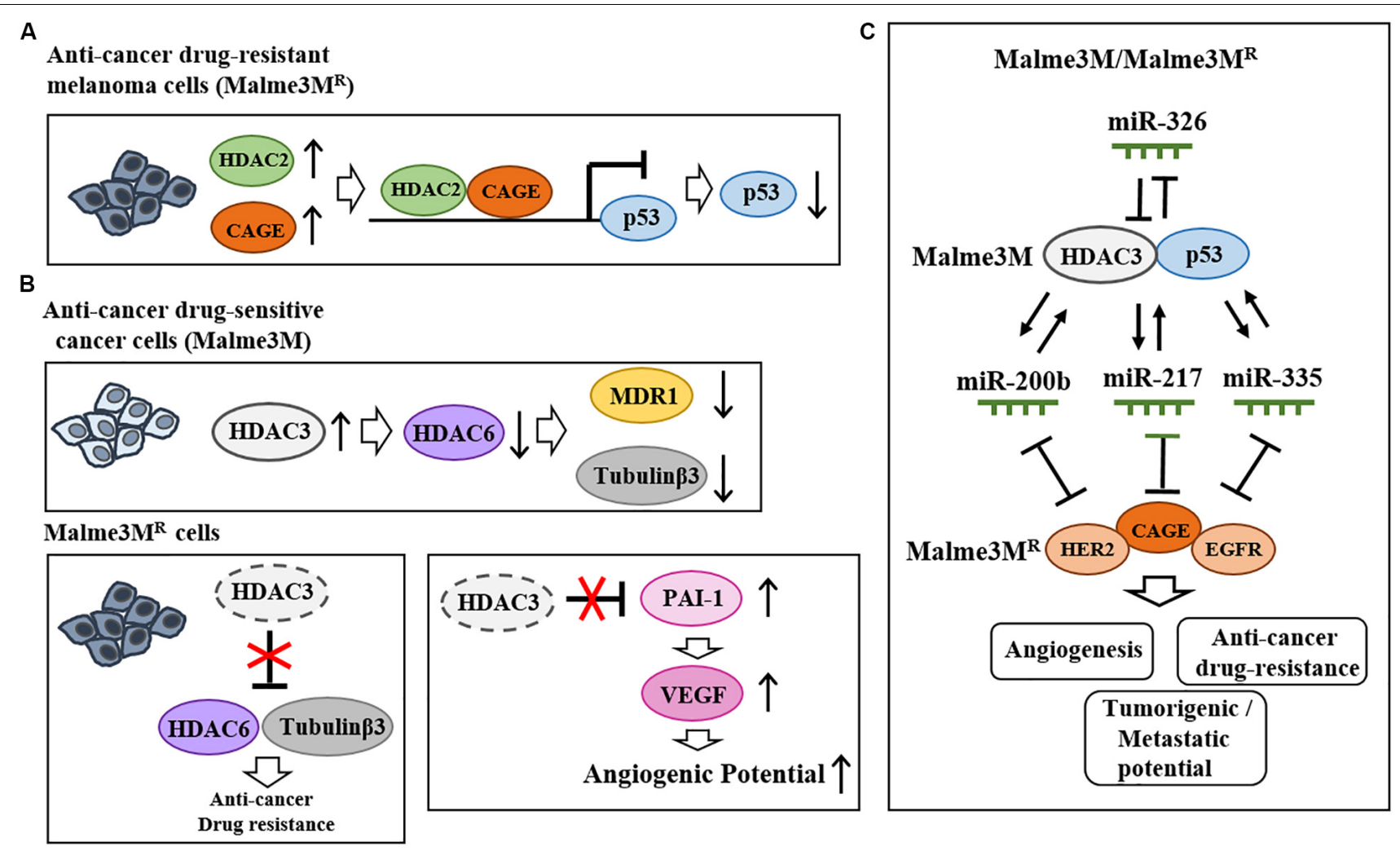

FIGURE 3 | Effects of HDACs on the responses to anti-cancer drugs and melanoma growth. (A) HDAC2 binds to cancer/testis antigen CAGE and directly regulates the expression of p53 to confer resistance to various anti-cancer drugs in melanoma cells (upper). (B) In Malme3M Cells, HDAC3 decreases the expression levels of HDAC6, MDR1, and tubulin $\beta 3$ (upper). In Malme3M ${ }^{R}$ cells, HDAC6 interacts with tubulin $\beta 3$ and confers resistance to anti-cancer drugs (lower). HDAC3 negatively regulates angiogenic potential by decreasing the expression levels of PAl-1 and VEGF (lower). (C) HDAC3 forms a negative feedback loop with miR-326 and regulates the response to anti-cancer drugs as well as the tumorigenic and metastatic potential of melanoma cells. HDAC3 forms positive feedback loops with miR-200b, miR-217, and miR-335 in Malme3M cells. These miRNAs negatively regulate the expression of CAGE. CAGE interacts with EGFR and HER2 and confers resistance to anti-cancer drugs.

anti-cancer drugs, including BRAF and MEK inhibitors. CAGEderived ${ }^{269} \mathrm{GTGKT}^{273}$ peptide binds to CAGE and enhances sensitivity to anti-cancer drugs in Malme $3 \mathrm{M}^{\mathrm{R}}$ cells (Kim et al., 2017). CAGE interacts with EGFR and human epidermal growth factor receptor 2 (HER2) to confer resistance to gefitinib and trastuzumab in Malme $3 \mathrm{M}^{\mathrm{R}}$ cells (Kim et al., 2016, Figure 3C). Thus, HDAC2-binding of CAGE can regulate the response to BRAF/MEK inhibitors. Table 1 shows the roles of HDACs in cancer cell proliferation, angiogenic potential, and metastasis.

The HDAC inhibitors vorinostat and valproic acid (VPA) decrease the migration potential of $B R A F^{V 600 E}$ mutant melanoma cells by increasing the expression of plasma membrane $\mathrm{Ca}^{2+}$ ATPase 4b (PMCA4b) (Hegedus et al., 2017). VPA increases acetylation of lysine residues of histone $\mathrm{H} 3$ at 9, 18, 23, and 27 at the promoter region of tissue type plasminogen activator (Larsson et al., 2012). Vorinostat induces $\mathrm{H} 3 \mathrm{~K} 9$ acetylation to exert anti-cancer effects in urothelial carcinoma cells (Eto et al., 2019), and decreases the tumorigenic potential of drug-resistant melanoma cells (Wang et al., 2018). The HDAC inhibitor panobinostat decreases PI3 kinase activity and increases the expression levels of apoptotic proteins such as BIM and NADPH oxidase activator (NOXA) (Gallagher et al., 2018). Panobinostat increases the acetylation of STAT3 at lysine 685 (Gupta et al., 2012). MS-275, an inhibitor of class I HDACs, increases H3K27ac and HDAC7 expression in breast cancer cells (Caslini et al., 2019). The class IIa-specific inhibitor MC-1568 increases the expression of $\mathrm{Rb}$ protein and the level of $\mathrm{H} 3 \mathrm{~K} 27$ at the Rb promoter (Rajan et al., 2018). The HDAC6-specific inhibitor ACY241 decreases the number of Treg cells $\left(\mathrm{CD} 4{ }^{+} \mathrm{CD} 25^{+} \mathrm{FoxP}^{+}\right)$, but increases the number of activated $\mathrm{CD}^{+} \mathrm{T}$ cells by activating AKT signaling to induce anti-cancer effects against multiple myeloma (Bae et al., 2018). HDAC6-specific inhibitors (Tubastatin A and Nexturastat) suppress melanoma cell proliferation by increasing the expression levels of tumor-associated antigens (TAAs) and human leukocyte antigen (HLA) class I (Woan et al., 2015). High levels of TAAs activate $\mathrm{CD}^{+} \mathrm{T}$ cells to suppress cancer progression (Qu et al., 2018). Tubastatin A increases acetylation of Cystathionine $\gamma$-lyase (CSE $\gamma$ ) at lysine 73 (Chi et al., 2019). These reports suggest that HDAC inhibitors can regulate responses to anti-cancer drugs.

Class I HDAC inhibitors, such as VPA or MS-275, enhance the sensitivity of melanoma cells to the alkylating agents temozolomide, dacarbazine, and fotemustine by 
TABLE 1 | Summary of functions of HDACs.

\begin{tabular}{|c|c|c|c|c|}
\hline HDAC & Target molecule & Function & Cancer type & References \\
\hline HDAC2 & P53 $\downarrow$ & Anti-cancer drug resistance $\uparrow$ & Melanoma & Kim et al., 2010 \\
\hline HDAC3 & Tubulin $\beta 3 \downarrow$, HDAC6 $\downarrow$ & Sensitivity to anti-cancer drugs $\uparrow$ & Melanoma & Kim et al., 2015 \\
\hline HDAC3 & PAI- $1 \downarrow$, VEGF $\downarrow$ & Angiogenic potential $\downarrow$ & Melanoma & Park et al., 2014 \\
\hline HDAC3 & $\operatorname{miR}-326 \downarrow$ & Sensitivity to anti-cancer drugs $\uparrow$ & Melanoma & Kim et al., 2014 \\
\hline HDAC5 & $\mathrm{HIF}-1 \uparrow$ & Invasion potential $\uparrow$ & Hepatocellular carcinoma & Ye et al., 2017 \\
\hline HDAC5 & CD9 $\downarrow$ & Metastatic potential $\uparrow$ & Neuroblastoma & Fabian et al., 2016 \\
\hline HDAC5 & - & Mesenchymal transition $\uparrow$ & Non-small cell lung cancer & Liu et al., 2017 \\
\hline HDAC5 & Deacetylation of SOX9 & Anti-cancer drug resistance $\uparrow$ & Breast cancer & Xue et al., 2019 \\
\hline HDAC6 & Binds to ERK1/2 & ERK1/2 activity $\uparrow$ & HEK 293 & Wu et al., 2018 \\
\hline HDAC6 & $\mathrm{ERK} 1 / 2 \uparrow$ & Apoptosis $\downarrow$, Proliferation $\uparrow$ & Melanoma & Liu et al., 2018 \\
\hline HDAC6 & Tubulin $\beta 3 \uparrow$ & Anti-cancer drug resistance $\uparrow$ & Melanoma & Kim et al., 2015 \\
\hline HDAC7 & Acetyl-H3K27 $\downarrow$ & Cancer stem cell phenotypes $\uparrow$ & Breast cancer & Caslini et al., 2019 \\
\hline HDAC8 & C-Jun $\uparrow$ & Anti-cancer drug resistance $\uparrow$ & Melanoma & Emmons et al., 2019 \\
\hline HDAC9 & - & Tumorigenic potential $\uparrow$ & Gastric cancer & Xiong et al., 2019 \\
\hline HDAC10 & PTPN22 $\downarrow$ & ERK $1 / 2$ activity $\uparrow$, Angiogenic potential $\uparrow$ & Endothelial cells & Duan et al., 2017 \\
\hline
\end{tabular}

suppressing the double strand break (DSB) repair pathway by decreasing the expression levels of RAD51 and fanconi anemia complementation group D2 (FANCD2) (Krumm et al., 2016). The combination of trichostatin A (TSA) with etoposide increases the expression of p53 and reverses resistance to chemotherapy in melanoma cells (Monte et al., 2006). These reports imply a role for HDAC inhibitors in the response to BRAF/MEK inhibitors.

The combination of a BRAF inhibitor, encorafenib, and an HDAC inhibitor, panobinostat, synergistically induces caspasedependent apoptotic cell death by inhibiting PI3 kinase activity and decreasing the expression levels of anti-apoptotic proteins (Gallagher et al., 2018). Vorinostat enhances sensitivity to dabrafenib and trametinib by increasing the level of reactive oxygen species (ROS) in anti-cancer drug-resistant melanoma cells (Wang et al., 2018). Vorinostat enhances the efficacy of BRAF/MEK inhibitors in N-RAS and NF-1 mutant melanomas by suppressing DNA repair pathways (Maertens et al., 2019). The HDAC8 inhibitor PCI-34051 enhances sensitivity to BRAF inhibitors by increasing the acetylation of c-jun at lysine 273 (Emmons et al., 2019). GPCR-mediated yes associated protein (YAP) activation and receptor tyrosine kinase (RTK)-driven AKT signaling confer resistance to MEK inhibition. The HDAC inhibitor panobinostat prevents MEK inhibition from activating YAP and AKT signaling (Faiao-Flores et al., 2019). These reports indicate that a combination of an HDAC inhibitor and a BRAF/MEK inhibitor may offer clinical benefits in patients with metastatic melanoma.

\section{THE ROLE OF IMMUNE CHECKPOINT IN MELANOMA GROWTH AND ANTI-CANCER DRUG RESISTANCE}

Cancer cells evade immune surveillance and progress by activating immune checkpoint pathways that suppress the antitumor immune responses by CTLs. Vemurafenibresistant $\left(V^{2} \mathrm{~m}^{\mathrm{R}}\right)$ cells display cross-resistance to melanoma antigen MART-specific CTLs and NK cells (Jazirehi et al., 2014). This indicates that lack of immune surveillance is responsible for resistance to BRAF inhibitors. Understanding the mechanisms of immune evasion is necessary for overcoming resistance to targeted and immune therapy. Immune checkpoint molecules, such as PD-1 and PD-L1, promote cancer progression by activating MDSCs and protumorigenic tumor-associated macrophages (TAMs or M2 macrophages), while inhibiting CTLs and NK cells. High PD-L1 expression is common in malignant melanomas (Wang et al., 2019). The expression levels of PD-L1 and PD1 can predict the outcome of anti-PD1 immune therapy in malignant melanoma (Ugurel et al., 2020). The $B R A F^{V 600 E}$ mutation leads to high PD-L1 level in a MEK-dependent manner (Feng D. et al., 2019).

Activation of EGFR-STAT3 signaling is responsible for the increased expression of PD-L1 in melanoma cells (Ehexige et al., 2020; Li et al., 2020, Figure 4A). The MAPK and PI3K/AKT signaling pathways regulate the expression of PD-L1 (Li et al., 2019, Figure 4A). Melanoma extracellular vesicles increase the expression of PD-L1 via TLR4 signaling and suppress CTL activity (Fleming et al., 2019). Various transcription factors, such as HIF-1 $\alpha$, STAT3, C-JUN, ad NF-кB, regulate the expression of PD-L1 (Figure 4A).

Treatment with the MEK inhibitor trametinib increases the expression of PD-L1 via STAT3 activation, which in turn enhances sensitivity to PD-L1 blockade (Kang et al., 2019, Figure 4B). Resistance to the MEK inhibitor BAY869766 results from increased expression of EGFR and PDL1 (Napolitano et al., 2019). Vemurafenib resistance results from the increased expression of PD-L1 by YAP, an effector of Hippo signaling, in melanoma cells (Kim et al., 2018, Figure 4B). These reports suggest that immune checkpoint molecules can determine melanoma growth and the response to anti-cancer drugs. 


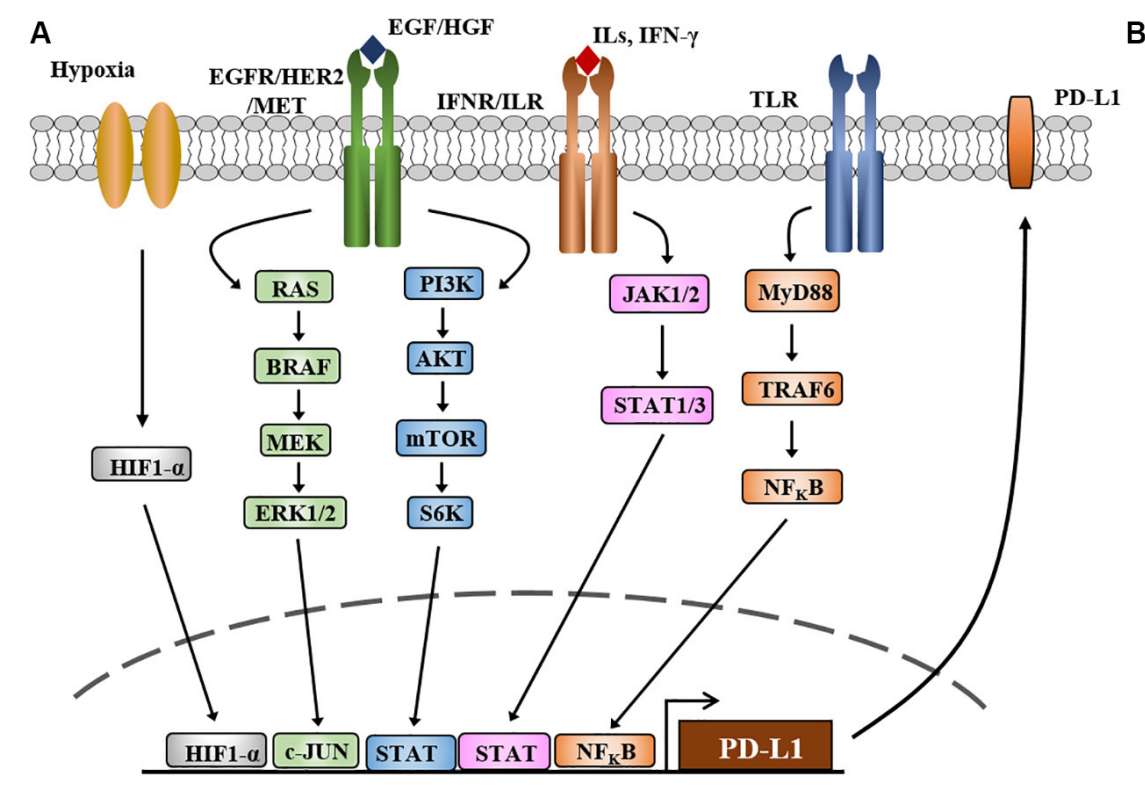

B Malignant cancer cells

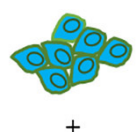

Trametinib<smiles>C1CCC2CCCC2C1</smiles>

STAT3 $\uparrow$

L

PD-L1 $\uparrow$

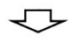

Sensitivity to

PD-L1 blockade $\uparrow$
Melanoma cells

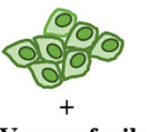

Vemurafenib

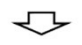

YAP $\uparrow$

Z

PD-L1 $\uparrow$

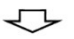

Vemurafenib

Resistance

FIGURE 4 | The expression and regulation of PD-L1and the role of PD-L1 in anti-cancer drug resistance. (A) Regulation of PD-L1 expression occurs at different levels. HIF-1 $\alpha$ directly increases the expression of PD-L1 by binding to the promoter sequences of PD-L1. Toll-like receptor signaling increases the expression of PD-L1 by NF-kB. PI3K/AKT/mTOR and RAS/RAF/MEK/ERK signaling increase the expression of PD-L1 by activating C-Jun and STAT3. JAK/STAT signaling activated by IFN- $\gamma$ increases the expression of PD-L1. (B) Treatment of metastatic melanomas with BRAF inhibitors or a combination of BRAF/MEK inhibitors leads to immune evasion (left). Increased expression of PD-L1 increases resistance to MEK inhibitors and EGFR-TKIs (left). MEKi denotes MEK inhibitor. EGFR-TKIs denote EGFR-tyrosine kinase inhibitors. Repeated exposure to vemurafenib increases the expression level of PD-L1, which in turn confers resistance to vemurafenib (right).

\section{HDAC INHIBITORS ACTIVATE IMMUNE SURVEILLANCE}

The tumor microenvironment consists of cancer cells and stromal cells (for example, cancer-associated fibroblasts, endothelial cells, and innate and adaptive immune cells). Cancer-associated fibroblasts induce phenotypic switching of melanoma cells into a mesenchymal-like phenotype and activate PI3K signaling to confer resistance to BRAF inhibitors (Seip et al., 2016). Therefore, cellular interactions within the tumor microenvironment may regulate the response to anti-cancer drugs. PD-1/PD-L1 interactions lead to immune evasion (tumor tolerance) by inactivating $\mathrm{CD}^{+} \mathrm{T}$ cells (Figure 5A). MDSCs interact with $\mathrm{CD} 8^{+} \mathrm{T}$ cells via $\mathrm{PD}-\mathrm{L} 1$ and inactivate $\mathrm{CD} 8^{+} \mathrm{T}$ cells by secreting TGF- $\beta$ and IL-10 (Fleming et al., 2018, Figure 5A). TAMs, which are activated by IFN- $\gamma$ released by $\mathrm{CD}^{+} \mathrm{T}$ helper cells, inactivate $\mathrm{CD}^{+} \mathrm{T}$ cells ( $\mathrm{Li}$ et al., 2020, Figure 5A). Melanoma cells activate MDSCs, but inactivate $\mathrm{CD}^{+} \mathrm{T}$ cells via PD-L1 (Figure 5A). Specific depletion of pro-tumorigenic $\mathrm{CD} 63^{+} \mathrm{M} 2$ macrophages (TAMs) leads to infiltration of CTLs and tumor regression (Etzerodt et al., 2019).

The combination of DNA methyltransferase (DNMT) and histone deacetylase inhibitors decreases the number of MDSCs through type I IFN signaling and activates $\mathrm{CD}^{+} \mathrm{T}$ and NK cell signaling (Stone et al., 2017). This implies that epigenetic modifications regulate interactions between cancer cells and immune cells. HDAC6-selective inhibitors (ricolinostat and citarinostat) enhance the anti-tumor effects of CTLs in melanoma patients by decreasing the expression of Forkhead
Box P3 (FOXP3) to suppress the functions of regulatory $\mathrm{T}$ cells (Laino et al., 2019, Figure 5B). The HDAC6 inhibitor ACY241 enhances the anti-tumor effects of antigen-specific $\mathrm{CD}^{+} \mathrm{T}$ cells by activating the AKT/mTOR/p65 pathways in solid tumors (Bae et al., 2018, Figure 5B). A combination of the HDAC inhibitor sodium butyrate and vemurafenib increases the expression of NK cell receptor (NKG2D)-ligand to enhance recognition of vemurafenib-treated melanoma cells by NK cells (Lopez-Cobo et al., 2018). MS-275 induces anti-tumorigenic M1 macrophage polarization through the IFN $-\gamma$ receptor/ STAT1 signaling pathway, and inhibits the function of MDSCs and eliminates antigen-negative cancer cells in a caspase-dependent manner (Nguyen et al., 2018, Figure 5B). The HDAC inhibitor vorinostat increases the expression levels of HLA classes I and II molecules on the cell surface to activate CTLs (Sun et al., 2019). These reports suggest that HDAC inhibitors may activate immune surveillance mechanism to suppress melanoma growth and enhance sensitivity to immune checkpoint inhibitors.

\section{HDAC INHIBITORS ENHANCE THE EFFICACY OF IMMUNE CHECKPOINT INHIBITORS}

Immune checkpoint inhibitors, such as anti-cytotoxic $\mathrm{T}$ Lymphocyte associated protein- 4 (CTLA-4) antibody (Ipilimumab) and anti-PD-L1 antibodies (atezolizumab, druvalumab, and avelumab) have shown some clinical benefits in the treatment of patients with advanced-stage metastatic 

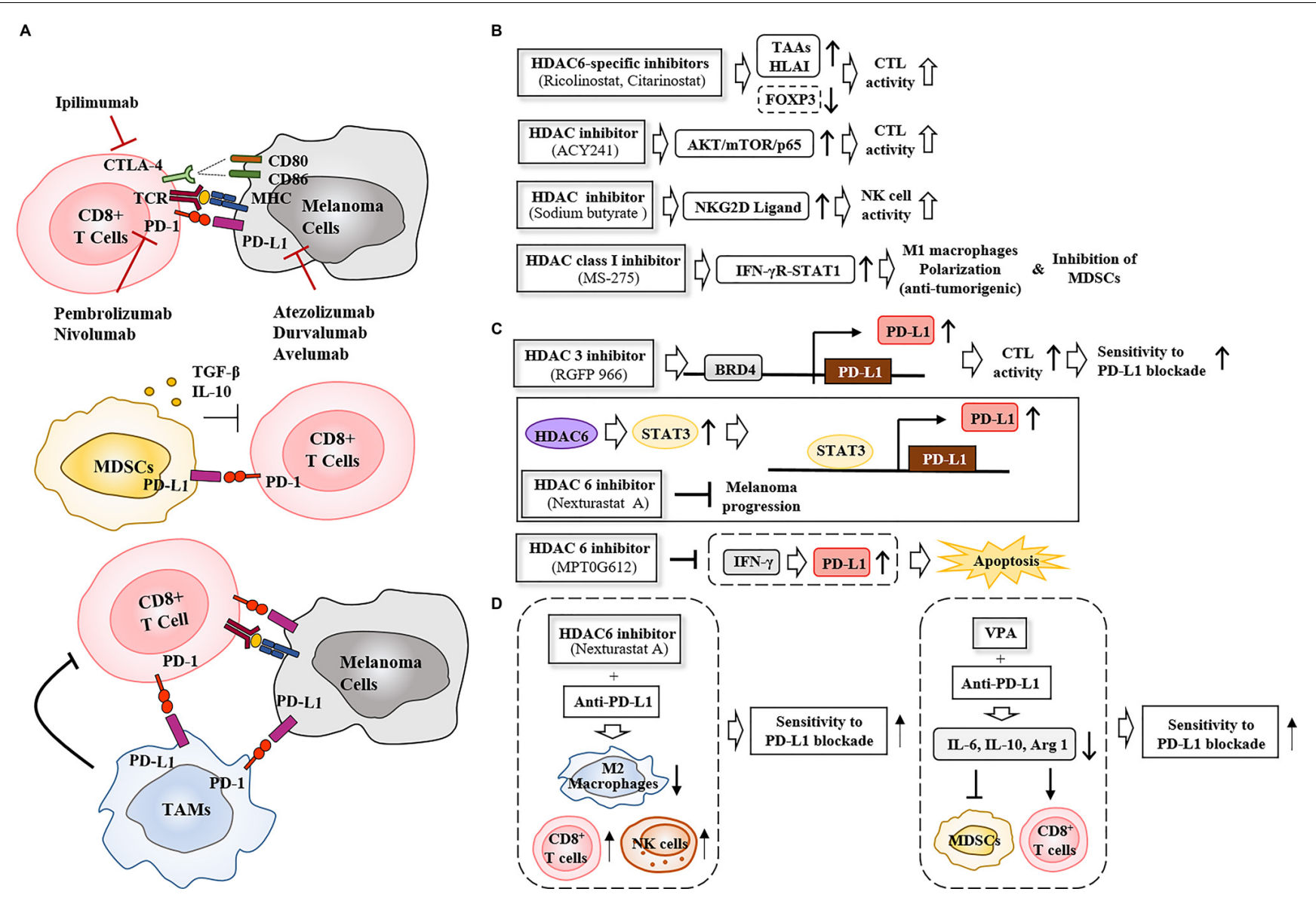

FIGURE 5 | HDAC inhibitors enhance sensitivity to immune checkpoint inhibitors by regulating anti-tumor immune responses. (A) PD-1/PD-L1 interactions between cancer cells and $\mathrm{CD}^{+}{ }^{+}$T cells suppress $\mathrm{T}$ cell activation, leading to tumor tolerance (upper). Ipilimumab, an anti-CTLA-4 antibody, disrupts the interaction between CTLA-4 and CD80/CD86, increasing production of pro-inflammatory cytokines and inducing T cell activation. MDSCs (middle) and TAMs (lower) suppress T cell activation via PD-1/PD-L1 interactions. MDSCs inhibit the function of CD8 ${ }^{+}$T cells by secreting TGF- $\beta$ and IL-10. (B) HDAC inhibitors enhance CTL and NK cell activity, induce M1 macrophage polarization, and suppress the immune regulatory function of MDSCs. (C) HDACs regulate the PD-L1 expression to induce CTL activity or apoptosis. BRD4 denotes bromo domain protein 4. (D) HDAC inhibitors enhance sensitivity to PD-L1 blockade by activating CD8 ${ }^{+}$T and NK cells while inactivating MDSCs and M2 macrophages. TAAs denote tumor associated antigens.

melanoma. The overall response to atezolizumab was $30 \%$ among 43 melanoma patients in a phase I clinical trial (Hamid et al., 2019). Anti-PD1 antibodies, such as nivolumab and pembrolizumab, are also widely used to treat advanced melanoma (Fujimura et al., 2019).

Epigenetic modifications regulate expression of the genes involved in immune surveillance. Bromodomain and extraterminal region (BET) protein recognizes acetylated lysines of histones and non-histone proteins (Rajendran et al., 2019). BET inhibitors suppress melanoma growth by decreasing the expression of PD-L1 while activating $\mathrm{CD}^{+} \mathrm{T}$ cells (Erkes et al., 2019). HDAC6 increases the expression of PD-L1 through STAT3 signaling, and selective inhibition of HDAC6 suppresses cancer progression in vivo (Lienlaf et al., 2016, Figure 5C). The inhibition of HDAC6 by MPT0G612 prevents IFN- $\gamma$ from increasing the expression of PD-L1 and induces apoptosis by suppressing autophagy (Chen et al., 2019, Figure 5C). RGFP966 increases the expression of PD-L1 in dendritic cells, and the combination of RGFP966 with anti-PD-L1 antibody suppresses murine lymphoma growth (Deng et al., 2019, Figure 5C).

The effect of immune checkpoint blockade is compromised by activation of MDSCs. A combination of the HDAC inhibitor VPA and anti-PD-L1 antibody inhibits functioning of MDSCs by decreasing the expression levels of IL-10, IL-6, and Arginase I (ARG1) while activating $\mathrm{CD}^{+} \mathrm{T}$ cells (Adeshakin et al., 2020, Figure 5D). The HDAC6 inhibitor nexturastat A improves the efficacy of anti-PD-1 antibody by decreasing the number of pro-tumorigenic M2 macrophages (TAMs) while increasing the number of tumor infiltrating NK cells and $\mathrm{CD}^{+} \mathrm{T}$ cells (Knox et al., 2019, Figure 5D). PD-1 blockade increases the expression of PD-L1 via pro-inflammatory cytokines such as IFN- $\gamma$ (Knox et al., 2019). Nexturastat A prevents anti-PD-1 antibody from increasing the expression of PD-L1 (Knox et al., 2019). These reports indicate that HDAC inhibitors enhance the responses to immune checkpoint inhibitors by activating immune surveillance. 
TABLE 2 | Clinical trials of HDAC inhibitors: characteristics of clinical trials registered in https://clinicaltrials.gov.

\begin{tabular}{|c|c|c|c|c|c|c|}
\hline Title & Treatment & Characteristics & Condition & Phase & Dates & NCT Number \\
\hline $\begin{array}{l}\text { Vorinostat in Treating Patients } \\
\text { With Metastatic or Unresectable } \\
\text { Melanoma }\end{array}$ & Vorinostat & $\begin{array}{l}\text { - Enrollment : } 32 \text { patients with } \\
\text { advanced melanoma } \\
\text { - Administration : dose of } 400 \mathrm{mg} \\
\text { for } 28 \text { consecutive days per cycle } \\
\text { - Adverse events : fatigue, nausea, } \\
\text { lymphopenia, and hyperglycemia } \\
\text { - Outcome : } 2 \text { partial response and } \\
16 \text { stable disease (median PFS of } \\
5 \text { months), } 14 \text { progressive } \\
\text { disease (median PFS of } \\
4 \text { months) }\end{array}$ & Melanoma & Phase 2 & $\begin{array}{l}\text { - Study Start : } \\
\text { September } 2005 \\
\text { - Study Completion : } \\
\text { June } 2013\end{array}$ & NCT00121225 \\
\hline $\begin{array}{l}\text { NPI-0052 and Vorinostat in } \\
\text { Patients With Non-small Cell } \\
\text { Lung Cancer, Pancreatic Cancer, } \\
\text { Melanoma or Lymphoma }\end{array}$ & $\begin{array}{l}\text { NPI-0052 (marizomib) } \\
\text { Vorinostat }\end{array}$ & $\begin{array}{l}\text { - Enrollment: } 22 \text { patients with } \\
\text { melanoma, pancreatic carcinoma } \\
\text { or Non-small Cell Lung Cancer } \\
\text { (NSCLC) } \\
\text { - Administration: doses of weekly } \\
\text { marizomib in combination with } \\
\text { vorinostat } 300 \text { mg daily for } \\
16 \text { days in } 28 \text { day cycles } \\
\text { - Adverse events : fatigue, nausea, } \\
\text { vomiting, diarrhea, anorexia, } \\
\text { dyspnoea, headache, infusion } \\
\text { site pain } \\
\text { - Outcome : } 61 \% \text { stable disease, } \\
\text { 39\% partial response }\end{array}$ & $\begin{array}{l}\text { Non-Small Cell Lung } \\
\text { CancerPancreatic } \\
\text { CancerMelanoma } \\
\text { LymphomaMultiple Myeloma }\end{array}$ & Phase 1 & $\begin{array}{l}\text { - Study Start : } \\
\text { March } 2008 \\
\text { - Study Completion : } \\
\text { January } 2010\end{array}$ & NCT00667082 \\
\hline $\begin{array}{l}\text { A Phase I Study of Belinostat in } \\
\text { Combination With Cisplatin and } \\
\text { Etoposide in Adults With Small } \\
\text { Cell Lung Carcinoma and Other } \\
\text { Advanced Cancers }\end{array}$ & $\begin{array}{l}\text { Belinostat Cisplatin } \\
\text { Etoposide }\end{array}$ & $\begin{array}{l}\text { - Enrollment : } 28 \text { patients with } \\
\text { histologically or cytologically } \\
\text { confirmed cancers for which } \\
\text { there is no known standard } \\
\text { therapy capable of extending life } \\
\text { expectancy } \\
\text { - Administration : doses of } \\
\text { belinostat } 400 \mathrm{mg} / \mathrm{m}^{2} \text { on days } \\
1 \text { and } 2 \text {, cisplatin } 80 \mathrm{mg} / \mathrm{m}^{2} \text { on } \\
\text { day } 2 \text {, and etoposide } 100 \mathrm{mg} / \mathrm{m}^{2} \\
\text { daily times } 3 \text { on days } 2 \text { to } 4 \\
\text { - Outcome : } 11 \text { partial response, } \\
13 \text { stable disease, and } 4 \\
\text { progressive disease }\end{array}$ & $\begin{array}{l}\text { Carcinoma NeuroendocrineSmall } \\
\text { Cell Lung CarcinomaMalignant } \\
\text { Epithelial Neoplasms }\end{array}$ & Phase 1 & $\begin{array}{l}\text { - Study Start : } \\
\text { July 1, } 2009 \\
\text { - Study Completion : } \\
\text { April 20, } 2018\end{array}$ & NCT00926640 \\
\hline
\end{tabular}


TABLE 2 | Continued

\begin{tabular}{|c|c|c|c|c|c|c|}
\hline Title & Treatment & Characteristics & Condition & Phase & Dates & NCT Number \\
\hline $\begin{array}{l}\text { Panobinostat (LBH589) in } \\
\text { Patients With Metastatic } \\
\text { Melanoma }\end{array}$ & Panobinostat & $\begin{array}{l}\text { - Enrollment : } 16 \text { patients with } \\
\text { metastatic melanoma that is } \\
\text { amenable to serial biopsies } \\
\text { - Administration : doses of } \\
\text { LBH589 three days a } \\
\text { week(Monday, Wednesday and } \\
\text { Friday) every other weak } \\
\text { - Adverse events : } \\
\text { thrombocytopenia, } \\
\text { lymphocytopenia, LFT elevation, } \\
\text { hypophosphatemia, hypokalemia } \\
\text { Outcome : } 27 \% \text { stable disease, } \\
73 \% \text { progressive disease }\end{array}$ & Malignant Melanoma & Phase 1 & $\begin{array}{l}\text { - Study Start : } \\
\text { February } 2010 \\
\text { - Study Completion : } \\
\text { March 13, } 2017\end{array}$ & NCT01065467 \\
\hline $\begin{array}{l}\text { A Safety and Dose-finding Study } \\
\text { of JNJ-26481585 for Patients } \\
\text { With Advanced Solid } \\
\text { Malignancies and Lymphoma. }\end{array}$ & Quisinostat & $\begin{array}{l}\text { - Enrollment : } 22 \text { with advanced } \\
\text { solid tumors or lymphomas that } \\
\text { were refractory to standard } \\
\text { therapy } \\
\text { - Administration : doses of } \\
\text { quisinostat once a day for } \\
21 \text { days cycle } \\
\text { - Adverse events: fatigue, cardiac } \\
\text { disorder, decreased appetite, } \\
\text { ventricular tachycardia, lethargy, } \\
\text { and vomiting } \\
\text { - Outcome: } 3 \text { partial response, and } \\
6 \text { stable disease }\end{array}$ & LymphomaNeoplasmsa & Phase 1 & $\begin{array}{l}\text { - Study Start : } \\
\text { August } 2007 \\
\text { - Study Completion : } \\
\text { September } 2011\end{array}$ & NCT00677105 \\
\hline $\begin{array}{l}\text { Selective HDAC6 Inhibitor } \\
\text { ACY-241 in Combination With } \\
\text { Ipilimumab and Nivolumab }\end{array}$ & $\begin{array}{l}\text { ACY-241 Nivolumab } \\
\text { Ipilimumab }\end{array}$ & $\begin{array}{l}\text { - Enrollment : } 1 \text { patient with } \\
\text { advanced melanoma } \\
\text { - Administration : doses of } \\
\text { ACY-241 in combination with } \\
\text { ipilimumab and nivolumab every } \\
3 \text { weeks for } 4 \text { doses each during } \\
\text { a 12-week }\end{array}$ & Malignant Melanoma & Phase 1 & $\begin{array}{l}\text { - Study Start : } \\
\text { September 30, } 2016 \\
\text { - Study Completion : } \\
\text { April 7, } 2017\end{array}$ & NCT02935790 \\
\hline $\begin{array}{l}\text { HDAC Inhibitor Vorinostat in } \\
\text { Resistant BRAF V600 Mutated } \\
\text { Advanced Melanoma }\end{array}$ & Vorinostat & $\begin{array}{l}\text { - Enrollment : } 21 \text { patients with } \\
\text { BRAF V600 mutated melanoma } \\
\text { who developed resistance to } \\
\text { BRAFi and/or BRAFi+MEKi } \\
\text { - Administration : dose of } \\
\text { vorinostat } 360 \text { mg once daily }\end{array}$ & Melanoma Skin Neoplasms & Phase 1Phase 2 & $\begin{array}{l}\text { - Study Start : } \\
\text { June } 2016 \\
\text { - Primary Completion : } \\
\text { October } 2019\end{array}$ & NCT02836548 \\
\hline
\end{tabular}




\section{CONCLUSION AND PERSPECTIVES}

To better understand the mechanisms of resistance to BRAF/MEK inhibitors in melanoma, identification of molecular signatures associated with resistance is necessary. Establishment of melanoma cell lines that are resistant to these inhibitors will make it possible to identify molecular signatures that may serve as targets for the development of anti-melanoma therapies.

MicroRNAs (miRNAs) are small non-coding RNAs that play important roles in cellular proliferation, anti-cancer drug resistance and cancer progression (Kim et al., 2017). miR-22 directly binds to the $3^{\prime}$ UTR of HDAC6 and suppresses cervical cancer cell proliferation (Wongjampa et al., 2018). miRNAs that target specific HDACs can overcome resistance to targeted and immune therapy. Downregulation of miR-589 promotes cancer malignancy by increasing PD-L1 expression level (Liu et al., 2017). miR-146a, which is increased in metastatic melanoma, induces immune evasion of melanoma cells (Mastroianni et al., 2019). The combination of a miR-146a inhibitor and anti-PD-L1 improves survival in a mouse model of melanoma (Mastroianni et al., 2019). It is necessary to identify miRNAs that bind to the $3^{\prime}$ UTR of PD-L1 and/or PD-1. These miRNAs can be developed as anti-melanoma therapies in combination with HDAC inhibitors and immune checkpoint inhibitors.

Epigenetic modifications regulate cancer progression and anti-cancer drug resistance. Epigenetic modifications are reversible and dynamic. Thus, targeting HDACs has emerged as an attractive strategy for the treatment of various cancers. Reportedly, HDACs regulate the expression levels of immune checkpoint molecules. Thus, targeting HDACs may prove to be an effective strategy to overcome resistance to immune checkpoint blockade.

The FDA has approved four HDAC inhibitors for use in cancer patients. These inhibitors are Vorinostat (hydroxamic acid family), Romidepsin (cyclic peptide family), Belinostat (hydroxamic acid family), and Panobinostat (hydroxamic acid family). These inhibitors have been approved for the treatment of cutaneous T-cell lymphoma and peripheral T cell lymphoma. In a phase II clinical trial, some patients with advanced melanoma displayed an early response to vorinostat. However, the disease state in most of these patients was stable (Haas et al., 2014). Vorinostat therapy has many side effects, including fatigue, nausea, and lymphopenia (Haas et al., 2014). Vorinostat and the proteasome inhibitor marizomib have synergistic effects when used together in cancer cell lines derived from melanoma patients and are well-tolerated by melanoma patients (Millward et al., 2012). The combination of belinostat (an inhibitor of HDACI and HDACII) with cisplatin and etoposide lea to hematologic toxicity in a phase I clinical trial of advanced small cell lung cancer patients (Balasubramaniam et al., 2018). The combination of romidepsin and the DNA methyl transferase I inhibitor 5-aza-deoxycydine displayed dose-limiting toxicity, including grade 4 thrombocytopenia, grade 4 neutropenia, and pleural effusion (O'Connor et al., 2019). The overall response rate to a combination of romidepsin and 5-azadeoxycydine in T-cell lymphoma patients was 55\% (O'Connor et al., 2019). A combination of romidepsin and the BET inhibitor IBET151 increases the expression of IL- 6 and the number of antigen-specific $\mathrm{CD}^{+}$cells during vaccination for the treatment of melanoma (Badamchi-Zadeh et al., 2018). Panobinostat (a pan-deacetylase inhibitor) showed a very low response rate and a highly toxic effects in phase I trial of patients with metastatic melanoma (Ibrahim et al., 2016). Panobinostat treatment was associated with high rates of nausea, vomiting, and fatigue in phase 1 trial of metastatic melanoma patients (Ibrahim et al., 2016). The combination of panobinostat and the proteasome inhibitor carfilzomib had adverse effects, including thrombocytopenia (41\%), fatigue $(17 \%)$, and nausea/vomiting (12\%) in a phase I trial of 32 patients with multiple myeloma (Kaufman et al., 2019). The objective response rate (ORR) and clinical benefit rate were 63 and $68 \%$, respectively in that same phase I trial of 32 patients with multiple myeloma (Kaufman et al., 2019). Quisinostat, hydroxamate-based HDAC inhibitor, targets both class I and II HDACs. According to the results of a phase I clinical trial, quisinostat shows strong antitumor effect and is well-tolerated in metastatic melanoma patients (Venugopal et al., 2013). Table 2 describes clinical trials of HDAC inhibitors in various cancers, including melanoma.

To date, there have been no successful clinical trials involving a combination of HDAC inhibitors and immune checkpoint inhibitors. The HDAC-selective inhibitors that are currently in use have off-target effects. To overcome these off target effects, it is necessary to design HDAC-specific inhibitor based on the structure of each HDAC. Identification of proteins that interact with individual HDACs may make it possible to devise new antimelanoma therapies. We previously reported that CAGE-binding peptide prevents CAGE from binding to GSK3 $\beta$ and enhances sensitivity to anti-cancer drugs (Kim et al., 2017). Identification of proteins that interact with individual HDACs is necessary for development of anti-melanoma therapies. Peptides that bind to each HDAC and prevent interactions between each HDAC and its binding partner may circumvent off-target effects and enhance sensitivity to targeted and immune therapies.

Due to tumor heterogeneity and plasticity, combination therapy is required for the treatment of cancers, including melanomas. HDACs play major roles in the regulation of immune checkpoint molecules, cancer cell proliferation, and activation of oncogenic signaling pathways. It is reasonable to conclude that HDAC inhibitors in combination with targeted therapies and immune therapies can be employed as anti-melanoma therapies.

\section{AUTHOR CONTRIBUTIONS}

DJ wrote the manuscript. MY made the figures and tables. HJ helped in editing. YK and $\mathrm{HJ}$ provided intellectual output in the manuscript.

\section{FUNDING}

This work was supported by National Research Foundation Grants (2020R1A2C1006996, 2017M3A9G7072417, and 2018R1D1A1B07043498), a grant from the BK21 plus Program. 


\section{REFERENCES}

Adeshakin, A. O., Yan, D., Zhang, M., Wang, L., Adeshakin, F. O., Liu, W., et al. (2020). Blockade of myeloid-derived suppressor cell function by valproic acid enhanced anti-PD-L1 tumor immunotherapy. Biochem. Biophys. Res. Commun. 522, 604-611. doi: 10.1016/j.bbrc.2019.11.155

Ahmed, F., and Haass, N. K. (2018). Microenvironment-driven dynamic heterogeneity and phenotypic plasticity as a mechanism of melanoma therapy resistance. Front. Oncol. 8:173. doi: 10.3389/fonc.2018.00173

Ahn, A., Chatterjee, A., and Eccles, M. R. (2017). The slow cycling phenotype: a growing problem for treatment resistance in melanoma. Mol. Cancer Ther. 16, 1002-1009. doi: 10.1158/1535-7163.MCT-16-0535

Al Emran, A., Marzese, D. M., Menon, D. R., Stark, M. S., Torrano, J., Hammerlindl, H., et al. (2018). Distinct histone modifications denote early stress-induced drug tolerance in cancer. Oncotarget 9, 8206-8222. doi: 10 . 18632/oncotarget. 23654

Ascierto, P. A., Dummer, R., Gogas, H. J., Flaherty, K. T., Arance, A., Mandala, M., et al. (2020a). Update on tolerability and overall survival in COLUMBUS: landmark analysis of a randomised phase 3 trial of encorafenib plus binimetinib vs vemurafenib or encorafenib in patients with BRAF V600-mutant melanoma. Eur. J. Cancer 126, 33-44. doi: 10.1016/j.ejca.2019.11.016

Ascierto, P. A., Lewis, K. D., Di Giacomo, A. M., Demidov, L., Mandala, M., Bondarenko, I., et al. (2020b). Prognostic impact of baseline tumour immune infiltrate on disease-free survival in patients with completely resected, BRAF(v600) mutation-positive melanoma receiving adjuvant vemurafenib. Ann. Oncol. 31, 153-159. doi: 10.1016/j.annonc.2019.10.002

Ascierto, P. A., McArthur, G. A., Dreno, B., Atkinson, V., Liszkay, G., Di Giacomo, A. M., et al. (2016). Cobimetinib combined with vemurafenib in advanced BRAF(V600)-mutant melanoma (coBRIM): updated efficacy results from a randomised, double-blind, phase 3 trial. Lancet Oncol. 17, 1248-1260. doi: 10.1016/S1470-2045(16)30122-X

Atzori, M. G., Ceci, C., Ruffini, F., Trapani, M., Barbaccia, M. L., Tentori, L., et al. (2020). Role of VEGFR-1 in melanoma acquired resistance to the BRAF inhibitor vemurafenib. J. Cell. Mol. Med. 24, 465-475. doi: 10.1111/jcmm. 14755

Badamchi-Zadeh, A., Moynihan, K. D., Larocca, R. A., Aid, M., Provine, N. M., Iampietro, M. J., et al. (2018). Combined HDAC and BET inhibition enhances melanoma vaccine immunogenicity and efficacy. J. Immunol. 201, 2744-2752. doi: 10.4049/jimmunol.1800885

Bae, J., Hideshima, T., Tai, Y. T., Song, Y., Richardson, P., Raje, N., et al. (2018). Histone deacetylase (HDAC) inhibitor ACY241 enhances anti-tumor activities of antigen-specific central memory cytotoxic $\mathrm{T}$ lymphocytes against multiple myeloma and solid tumors. Leukemia 32, 1932-1947. doi: 10.1038/s41375-0180062-8

Balasubramaniam, S., Redon, C. E., Peer, C. J., Bryla, C., Lee, M. J., Trepel, J. B., et al. (2018). Phase I trial of belinostat with cisplatin and etoposide in advanced solid tumors, with a focus on neuroendocrine and small cell cancers of the lung. Anticancer Drugs 29, 457-465. doi: 10.1097/CAD.0000000000000596

Booth, L., Roberts, J. L., Sander, C., Lee, J., Kirkwood, J. M., Poklepovic, A., et al. (2017). The HDAC inhibitor AR42 interacts with pazopanib to kill trametinib/dabrafenib-resistant melanoma cells in vitro and in vivo. Oncotarget 8, 16367-16386. doi: 10.18632/oncotarget.14829

Caslini, C., Hong, S., Ban, Y. J., Chen, X. S., and Ince, T. A. (2019). HDAC7 regulates histone 3 lysine 27 acetylation and transcriptional activity at superenhancer-associated genes in breast cancer stem cells. Oncogene 38, 6599-6614. doi: 10.1038/s41388-019-0897-0

Chapman, P. B., Hauschild, A., Robert, C., Haanen, J. B., Ascierto, P., Larkin, J., et al. (2011). Improved survival with vemurafenib in melanoma with BRAF V600E mutation. N. Engl. J. Med. 364, 2507-2516. doi: 10.1056/ NEJMoa1103782

Chen, M. C., Lin, Y. C., Liao, Y. H., Liou, J. P., and Chen, C. H. (2019). MPT0G612, a Novel HDAC6 inhibitor, induces apoptosis and suppresses IFN-gammainduced programmed death-Ligand 1 in human colorectal carcinoma cells. Cancers 11:1617. doi: 10.3390/cancers11101617

Chi, Z., Byeon, H. E., Seo, E., Nguyen, Q. T., Lee, W., Jeong, Y., et al. (2019). Histone deacetylase 6 inhibitor tubastatin A attenuates angiotensin II-induced hypertension by preventing cystathionine gamma-lyase protein degradation. Pharmacol. Res. 146:104281. doi: 10.1016/j.phrs.2019.104281
Chodurek, E., Kulczycka, A., Orchel, A., Aleksander-Konert, E., and Dzierzewicz, Z. (2014). Effect of valproic acid on the proliferation and apoptosis of the human melanoma G-361 cell line. Acta Pol. Pharm. 71, 917-921.

Dembla, V., Groisberg, R., Hess, K., Fu, S., Wheler, J., Hong, D. S., et al. (2017). Outcomes of patients with sarcoma enrolled in clinical trials of pazopanib combined with histone deacetylase, mTOR, Her2, or MEK inhibitors. Sci. Rep. 7:15963. doi: 10.1038/s41598-017-13114-8

Deng, S., Hu, Q., Zhang, H., Yang, F., Peng, C., and Huang, C. (2019). HDAC3 inhibition upregulates PD-L1 expression in B-cell lymphomas and augments the efficacy of anti-PD-L1 therapy. Mol. Cancer Ther. 18, 900-908. doi: 10.1158/ 1535-7163.MCT-18-1068

Dikshit, A., Jin, Y. J., Degan, S., Hwang, J., Foster, M. W., Li, C. Y., et al. (2018). UBE2N promotes melanoma growth via MEK/FRA1/SOX10 signaling. Cancer Res. 78, 6462-6472.

Dratkiewicz, E., Simiczyjew, A., Pietraszek-Gremplewicz, K., Mazurkiewicz, J., and Nowak, D. (2019). Characterization of melanoma cell lines resistant to vemurafenib and evaluation of their responsiveness to EGFR- and METinhibitor treatment. Int. J. Mol. Sci. 21:113. doi: 10.3390/ijms21010113

Duan, B., Ye, D., Zhu, S., Jia, W., Lu, C., Wang, G., et al. (2017). HDAC10 promotes angiogenesis in endothelial cells through the PTPN22/ERK axis. Oncotarget 8, 61338-61349. doi: 10.18632/oncotarget.18130

Dummer, R., Ascierto, P. A., Gogas, H. J., Arance, A., Mandala, M., Liszkay, G., et al. (2018). Overall survival in patients with BRAF-mutant melanoma receiving encorafenib plus binimetinib versus vemurafenib or encorafenib (COLUMBUS): a multicentre, open-label, randomised, phase 3 trial. Lancet Oncol. 19, 1315-1327. doi: 10.1016/S1470-2045(18)30497-2

Ehexige, E., Bao, M., Bazarjav, P., Yu, X., Xiao, H., Han, S., et al. (2020). Silencing of STAT3 via peptidomimetic LNP-mediated systemic delivery of RNAi downregulates PD-L1 and inhibits melanoma growth. Biomolecules 10:285. doi: 10.3390/biom10020285

Emmons, M. F., Faiao-Flores, F., Sharma, R., Thapa, R., Messina, J. L., Becker, J. C., et al. (2019). HDAC8 regulates a stress response pathway in melanoma to mediate escape from BRAF inhibitor therapy. Cancer Res. 79, 2947-2961.

Emran, A. A., Marzese, D. M., Menon, D. R., Hammerlindl, H., Ahmed, F., Richtig, E., et al. (2019). Commonly integrated epigenetic modifications of differentially expressed genes lead to adaptive resistance in cancer. Epigenomics 11, 732-737. doi: 10.2217/epi-2018-0173

Erkes, D. A., Field, C. O., Capparelli, C., Tiago, M., Purwin, T. J., Chervoneva, I. et al. (2019). The next-generation BET inhibitor, PLX51107, delays melanoma growth in a CD8-mediated manner. Pigment Cell Melanoma Res. 32, 687-696. doi: $10.1111 / \mathrm{pcmr} .12788$

Eto, S., Saeki, K., Yoshitake, R., Yoshimoto, S., Shinada, M., Ikeda, N., et al. (2019). Anti-tumor effects of the histone deacetylase inhibitor vorinostat on canine urothelial carcinoma cells. PLoS One 14:e0218382. doi: 10.1371/journal.pone. 0218382

Etzerodt, A., Tsalkitzi, K., Maniecki, M., Damsky, W., Delfini, M., Baudoin, E., et al. (2019). Specific targeting of CD163(+) TAMs mobilizes inflammatory monocytes and promotes T cell-mediated tumor regression. J. Exp. Med. 216, 2394-2411. doi: 10.1084/jem.20182124

Fabian, J., Opitz, D., Althoff, K., Lodrini, M., Hero, B., Volland, R., et al. (2016). MYCN and HDAC5 transcriptionally repress CD9 to trigger invasion and metastasis in neuroblastoma. Oncotarget 7, 66344-66359. doi: 10.18632/ oncotarget.11662

Faiao-Flores, F., Emmons, M. F., Durante, M. A., Kinose, F., Saha, B., Fang, B., et al. (2019). HDAC inhibition enhances the in vivo efficacy of MEK inhibitor therapy in Uveal Melanoma. Clin. Cancer Res. 25, 5686-5701. doi: 10.1158/1078-0432. CCR-18-3382

Feng, D., Qin, B., Pal, K., Sun, L., Dutta, S., Dong, H., et al. (2019). BRAFV600E induced, tumor intrinsic PD-L1 can regulate chemotherapy-induced apoptosis in human colon cancer cells and in tumor xenografts. Oncogene 38, 6752-6766. doi: 10.1038/s41388-019-0919-y

Feng, T., Golji, J., Li, A., Zhang, X., Ruddy, D. A., Rakiec, D. P., et al. (2019). Distinct transcriptional programming drive response to MAPK inhibition in BRAF (V600)-Mutant Melanoma Patient-Derived Xenografts. Mol. Cancer Ther. 18, 2421-2432. doi: 10.1158/1535-7163.MCT-19-0028

Ferrante, F., Giaimo, B. D., Bartkuhn, M., Zimmermann, T., Close, V., Mertens, D., et al. (2020). HDAC3 functions as a positive regulator in Notch signal transduction. Nucleic Acids Res. 48, 3496-3512. doi: 10.1093/nar/gkaa088 
Fleming, V., Hu, X., Weber, R., Nagibin, V., Groth, C., Altevogt, P., et al. (2018). Targeting myeloid-derived suppressor cells to bypass tumor-induced immunosuppression. Front. Immunol. 9:398. doi: 10.3389/fimmu.2018.00398

Fleming, V., Hu, X., Weller, C., Weber, R., Groth, C., Riester, Z., et al. (2019). Melanoma extracellular vesicles generate immunosuppressive myeloid cells by upregulating PD-L1 via TLR4 signaling. Cancer Res. 79, 4715-4728. doi: 10. 1158/0008-5472.CAN-19-0053

Freeman, A. J., Vervoort, S. J., Ramsbottom, K. M., Kelly, M. J., Michie, J., Pijpers, L., et al. (2019). Natural killer cells suppress T cell-associated tumor immune evasion. Cell Rep. 28, 2784-2794.e5. doi: 10.1016/j.celrep.2019.08.017

Fujimura, T., Hidaka, T., Kambayashi, Y., and Aiba, S. (2019). BRAF kinase inhibitors for treatment of melanoma: developments from early-stage animal studies to Phase II clinical trials. Expert Opin. Investig. Drugs 28, 143-148. doi: 10.1080/13543784.2019.1558442

Gallagher, S. J., Gunatilake, D., Beaumont, K. A., Sharp, D. M., Tiffen, J. C., Heinemann, A., et al. (2018). HDAC inhibitors restore BRAF-inhibitor sensitivity by altering PI3K and survival signalling in a subset of melanoma. Int. J. Cancer 142, 1926-1937. doi: 10.1002/ijc.31199

Gameiro, S. R., Malamas, A. S., Tsang, K. Y., Ferrone, S., and Hodge, J. W. (2016). Inhibitors of histone deacetylase 1 reverse the immune evasion phenotype to enhance T-cell mediated lysis of prostate and breast carcinoma cells. Oncotarget 7, 7390-7402. doi: 10.18632/oncotarget.7180

Golan, T., and Levy, C. (2019). Negative regulatory loop between microphthalmiaassociated transcription factor (MITF) and notch signaling. Int. J. Mol. Sci. 20:576. doi: 10.3390/ijms20030576

Granados, K., Huser, L., Federico, A., Sachindra, S., Wolff, G., Hielscher, T., et al. (2020). T-type calcium channel inhibition restores sensitivity to MAPK inhibitors in de-differentiated and adaptive melanoma cells. Br. J. Cancer 122, 1023-1036. doi: 10.1038/s41416-020-0751-8

Green, R., Howell, M., Khalil, R., Nair, R., Yan, J., Foran, E., et al. (2019). Actinomycin D and telmisartan combination targets lung cancer stem cells through the Wnt/Beta catenin pathway. Sci. Rep. 9:18177. doi: 10.1038/s41598019-54266-z

Guan, X. W., Wang, H. Q., Ban, W. W., Chang, Z., Chen, H. Z., Jia, L., et al. (2020). Novel HDAC inhibitor Chidamide synergizes with Rituximab to inhibit diffuse large B-cell lymphoma tumour growth by upregulating CD20. Cell Death Dis. 11:20. doi: 10.1038/s41419-019-2210-0

Guo, Y., Zhang, X., Zeng, W., Zhang, J., Cai, L., Wu, Z., et al. (2020). TRAF6 activates fibroblasts to cancer-associated fibroblasts (CAFs) through FGF19 in tumor microenvironment to benefit the malignant phenotype of melanoma cells. J Invest Dermatol. doi: 10.1016/j.jid.2020.03.950 [Epub ahead of print].

Gupta, M., Han, J. J., Stenson, M., Wellik, L., and Witzig, T. E. (2012). Regulation of STAT3 by histone deacetylase- 3 in diffuse large B-cell lymphoma: implications for therapy. Leukemia 26, 1356-1364. doi: 10.1038/leu.2011.340

Haas, N. B., Quirt, I., Hotte, S., McWhirter, E., Polintan, R., Litwin, S., et al. (2014). Phase II trial of vorinostat in advanced melanoma. Invest. New Drugs 32, 526-534. doi: 10.1007/s10637-014-0066-9

Halasa, M., Wawruszak, A., Przybyszewska, A., Jaruga, A., Guz, M., Kalafut, J., et al. (2019). H3K18Ac as a marker of cancer progression and potential target of anti-cancer therapy. Cells 8:485. doi: 10.3390/cells8050485

Hamid, O., Molinero, L., Bolen, C. R., Sosman, J. A., Munoz-Couselo, E., Kluger, H. M., et al. (2019). Safety, clinical activity, and biological correlates of response in patients with metastatic melanoma: results from a phase I trial of Atezolizumab. Clin. Cancer Res. 25, 6061-6072. doi: 10.1158/1078-0432.CCR18-3488

Hartman, M. L., Sztiller-Sikorska, M., Gajos-Michniewicz, A., and Czyz, M. (2020). Dissecting mechanisms of melanoma resistance to BRAF and MEK inhibitors revealed genetic and non-genetic patient- and drug-specific alterations and remarkable phenotypic plasticity. Cells 9:142. doi: 10.3390/cells901 0142

Hegedus, L., Padanyi, R., Molnar, J., Paszty, K., Varga, K., Kenessey, I., et al. (2017). Histone deacetylase inhibitor treatment increases the expression of the plasma membrane $\mathrm{Ca}^{2+}$ Pump PMCA4b and inhibits the migration of melanoma cells independent of ERK. Front. Oncol. 7:95. doi: 10.3389/fonc.2017.00095

Hei, Y., Teng, B., Zeng, Z., Zhang, S., Li, Q., Pan, J., et al. (2020). Multifunctional immunoliposomes combining catalase and PD-L1 antibodies overcome tumor hypoxia and enhance immunotherapeutic effects against melanoma. Int. J. Nanomed. 15, 1677-1691. doi: 10.2147/IJN.S225807
Ibrahim, N., Buchbinder, E. I., Granter, S. R., Rodig, S. J., Giobbie-Huredr, A., Becerra, C., et al. (2016). A phase I trial of panobinostat (LBH 589) in patients with metastatic melanoma. Cancer Med. 5, 3041-3050. doi: 10.1002/cam4.862

Jazirehi, A. R., Nazarian, R., Torres-Collado, A. X., and Economou, J. S. (2014). Aberrant apoptotic machinery confers melanoma dual resistance to BRAF(V600E) inhibitor and immune effector cells: immunosensitization by a histone deacetylase inhibitor. Am. J. Clin. Exp. Immunol. 3, 43-56.

Jiang, B. P., Zhang, L., Guo, X. L., Shen, X. C., Wang, Y., Zhu, Y., et al. (2017). Poly(N-phenylglycine)-based nanoparticles as highly effective and targeted near-infrared photothermal therapy/photodynamic therapeutic agents for malignant melanoma. Small 13:1602496. doi: 10.1002/smll.201602496

Kalal, B. S., Pai, V. R., Behera, S. K., and Somashekarappa, H. M. (2019). HDAC2 inhibitor valproic acid increases radiation sensitivity of drug-resistant melanoma cells. Med. Sci. 7:51. doi: 10.3390/medsci7030051

Kang, S. H., Keam, B., Ahn, Y. O., Park, H. R., Kim, M., Kim, T. M., et al. (2019). Inhibition of MEK with trametinib enhances the efficacy of anti-PDL1 inhibitor by regulating anti-tumor immunity in head and neck squamous cell carcinoma. Oncoimmunology 8:e1515057. doi: 10.1080/2162402X.2018. 1515057

Kaufman, J. L., Mina, R., Jakubowiak, A. J., Zimmerman, T. L., Wolf, J. J., Lewis, C., et al. (2019). Combining carfilzomib and panobinostat to treat relapsed/refractory multiple myeloma: results of a Multiple Myeloma Research Consortium Phase I Study. Blood Cancer J. 9:3. doi: 10.1038/s41408-018-01548

Keilholz, U., Mehnert, J. M., Bauer, S., Bourgeois, H., Patel, M. R., Gravenor, D., et al. (2019). Avelumab in patients with previously treated metastatic melanoma: phase $1 \mathrm{~b}$ results from the JAVELIN Solid Tumor trial. J. Immunother. Cancer 7:12. doi: 10.1186/s40425-018-0459-y

Kim, M. H., Kim, C. G., Kim, S. K., Shin, S. J., Choe, E. A., Park, S. H., et al. (2018). YAP-induced PD-L1 expression drives immune evasion in BRAFi-resistant melanoma. Cancer Immunol. Res. 6, 255-266. doi: 10.1158/2326-6066.CIR-170320

Kim, Y., Kim, H., and Jeoung, D. (2015). Tubulin Beta3 serves as a target of HDAC3 and mediates resistance to microtubule-targeting drugs. Mol. Cells 38, 705-714. doi: 10.14348/molcells.2015.0086

Kim, Y., Kim, H., Park, D., Han, M., Lee, H., Lee, Y. S., et al. (2016). miR217 and CAGE form feedback loop and regulates the response to anti-cancer drugs through EGFR and HER2. Oncotarget 7, 10297-10321. doi: 10.18632/ oncotarget.7185

Kim, Y., Kim, H., Park, D., Lee, H., Lee, Y. S., Choe, J., et al. (2017). The pentapeptide Gly-Thr-Gly-Lys-Thr confers sensitivity to anti-cancer drugs by inhibition of CAGE binding to GSK3beta and decreasing the expression of cyclinD1. Oncotarget 8, 13632-13651. doi: 10.18632/oncotarget.14621

Kim, Y., Kim, H., Park, H., Park, D., Lee, H., Lee, Y. S., et al. (2014). miR-326histone deacetylase-3 feedback loop regulates the invasion and tumorigenic and angiogenic response to anti-cancer drugs. J. Biol. Chem. 289, 28019-28039. doi: 10.1074/jbc.M114.578229

Kim, Y., Park, H., Park, D., Lee, Y. S., Choe, J., Hahn, J. H., et al. (2010). Cancer/testis antigen CAGE exerts negative regulation on p53 expression through HDAC2 and confers resistance to anti-cancer drugs. J. Biol. Chem. 285, 25957-25968. doi: 10.1074/jbc.M109.095950

Knox, T., Sahakian, E., Banik, D., Hadley, M., Palmer, E., Noonepalle, S., et al. (2019). Selective HDAC6 inhibitors improve anti-PD-1 immune checkpoint blockade therapy by decreasing the anti-inflammatory phenotype of macrophages and down-regulation of immunosuppressive proteins in tumor cells. Sci. Rep. 9:6136. doi: 10.1038/s41598-019-42237-3

Krayem, M., Aftimos, P., Najem, A., van den Hooven, T., van den Berg, A., Hovestad-Bijl, L., et al. (2020). Kinome profiling to predict sensitivity to MAPK inhibition in melanoma and to provide new insights into intrinsic and acquired mechanism of resistance short title: sensitivity prediction to MAPK inhibitors in melanoma. Cancers 12:512. doi: 10.3390/cancers12020512

Krumm, A., Barckhausen, C., Kucuk, P., Tomaszowski, K. H., Loquai, C., Fahrer, J., et al. (2016). Enhanced histone deacetylase activity in malignant melanoma provokes RAD51 and FANCD2-triggered drug resistance. Cancer Res. 76, 3067-3077.

Lai, F., Jin, L., Gallagher, S., Mijatov, B., Zhang, X. D., and Hersey, P. (2012). Histone deacetylases (HDACs) as mediators of resistance to apoptosis in melanoma and as targets for combination therapy with selective BRAF 
inhibitors. Adv. Pharmacol. 65, 27-43. doi: 10.1016/B978-0-12-397927-8. 00002-6

Laino, A. S., Betts, B. C., Veerapathran, A., Dolgalev, I., Sarnaik, A., Quayle, S. N., et al. (2019). HDAC6 selective inhibition of melanoma patient T-cells augments anti-tumor characteristics. J. Immunother. Cancer 7:33. doi: 10.1186/s40425019-0517-0

Larsson, P., Ulfhammer, E., Magnusson, M., Bergh, N., Lunke, S., El-Osta, A., et al. (2012). Role of histone acetylation in the stimulatory effect of valproic acid on vascular endothelial tissue-type plasminogen activator expression. PLoS One 7:e31573. doi: 10.1371/journal.pone.0031573

Lee, B. S., Kim, Y. S., Kim, H. J., Kim, D. H., Won, H. R., Kim, Y. S., et al. (2018). HDAC4 degradation by combined TRAIL and valproic acid treatment induces apoptotic cell death of TRAIL-resistant head and neck cancer cells. Sci. Rep. 8:12520. doi: 10.1038/s41598-018-31039-8

Li, X., Fu, Y., Yang, B., Guo, E., Wu, Y., Huang, J., et al. (2020). BRD4 inhibition by AZD5153 promotes antitumor immunity via depolarizing M2 macrophages. Front. Immunol. 11:89. doi: 10.3389/fimmu.2020.00089

Li, X., Wu, Z., An, X., Mei, Q., Bai, M., Hanski, L., et al. (2017). Blockade of the LRP16-PKR-NF-kappaB signaling axis sensitizes colorectal carcinoma cells to DNA-damaging cytotoxic therapy. eLife 6:e27301. doi: 10.7554/eLife.27301

Li, Z., Zhou, J., Zhang, J., Li, S., Wang, H., and Du, J. (2019). Cancer-associated fibroblasts promote PD-L1 expression in mice cancer cells via secreting CXCL5. Int. J. Cancer 145, 1946-1957. doi: 10.1002/ijc.32278

Lienlaf, M., Perez-Villaroel, P., Knox, T., Pabon, M., Sahakin, E., Powers, J. et al. (2016). Essential role of HDAC6 in the regulation of PD-L1 in melanoma. Mol. Oncol. 10, 735-750. doi: 10.1016/j.molonc.2015.12.012

Liu, C., Lv, D., Li, M., Zhang, X., Sun, G., Bai, Y., et al. (2017). Hypermethylation of miRNA-589 promoter leads to upregulation of HDAC5 which promotes malignancy in non-small cell lung cancer. Int. J. Oncol. 50, 2079-2090. doi: 10.3892/ijo.2017.3967

Liu, J., Gu, J., Feng, Z., Yang, Y., Zhu, N., Lu, W., et al. (2016). Both HDAC5 and HDAC6 are required for the proliferation and metastasis of melanoma cells. J. Transl. Med. 14:7. doi: 10.1186/s12967-015-0753-0

Liu, J., Luan, W., Zhang, Y., Gu, J., Shi, Y., Yang, Y., et al. (2018). HDAC6 interacts with PTPN1 to enhance melanoma cells progression. Biochem. Biophys. Res. Commun. 495, 2630-2636. doi: 10.1016/j.bbrc.2017.12.145

Long, G. V., Hauschild, A., Santinami, M., Atkinson, V., Mandala, M., ChiarionSileni, V., et al. (2017). Adjuvant dabrafenib plus trametinib in stage III BRAF-mutated melanoma. N. Engl. J. Med. 377, 1813-1823. doi: 10.1056/ NEJMoa1708539

Lopez-Cobo, S., Pieper, N., Campos-Silva, C., Garcia-Cuesta, E. M., Reyburn, H. T., Paschen, A., et al. (2018). Impaired NK cell recognition of vemurafenib-treated melanoma cells is overcome by simultaneous application of histone deacetylase inhibitors. Oncoimmunology 7:e1392426. doi: 10.1080/2162402X.2017.1392426

Lorenzi, M., Arndorfer, S., Aguiar-Ibanez, R., Scherrer, E., Liu, F. X., and Krepler, C. (2019). An indirect treatment comparison of the efficacy of pembrolizumab versus competing regimens for the adjuvant treatment of stage III melanoma. J. Drug Assess. 8, 135-145. doi: 10.1080/21556660.2019.1649266

Louveau, B., Jouenne, F., Reger de Moura, C., Sadoux, A., Baroudjian, B., Delyon, J., et al. (2019). Baseline genomic features in BRAFV600-mutated metastatic melanoma patients treated with BRAF inhibitor + MEK inhibitor in routine care. Cancers 11:1203. doi: 10.3390/cancers11081203

Luo, C., Balsa, E., Perry, E. A., Liang, J., Tavares, C. D., Vazquez, F., et al. (2020). H3K27me3-mediated PGC1á Gene Silencing Promotes Melanoma Invasion Through WNT5A and YAP. J. Clin. Invest. 30, 853-862. doi: 10.1172/JCI130038

Maertens, O., Kuzmickas, R., Manchester, H. E., Emerson, C. E., Gavin, A. G., Guild, C. J., et al. (2019). MAPK pathway suppression unmasks latent DNA repair defects and confers a chemical synthetic vulnerability in BRAF-, NRAS-, and NF1-mutant melanomas. Cancer Discov. 9, 526-545.

Mastroianni, J., Stickel, N., Andrlova, H., Hanke, K., Melchinger, W., Duquesne, S., et al. (2019). miR-146a controls immune response in the melanoma microenvironment. Cancer Res. 79, 183-195.

Mazzio, E. A., and Soliman, K. F. A. (2018). Whole-transcriptomic Profile of SK-MEL-3 melanoma cells treated with the histone deacetylase inhibitor: trichostatin A. Cancer Genomics Proteomics 15, 349-364. doi: 10.21873/cgp. 20094

Millward, M., Price, T., Townsend, A., Sweeney, C., Spencer, A., Sukumaran, S., et al. (2012). Phase 1 clinical trial of the novel proteasome inhibitor marizomib with the histone deacetylase inhibitor vorinostat in patients with melanoma, pancreatic and lung cancer based on in vitro assessments of the combination. Invest. New Drugs 30, 2303-2317. doi: 10.1007/s10637-011-9766-6

Monte, M., Simonatto, M., Peche, L. Y., Bublik, D. R., Gobessi, S., Pierotti, M. A., et al. (2006). MAGE-A tumor antigens target p53 transactivation function through histone deacetylase recruitment and confer resistance to chemotherapeutic agents. Proc. Natl. Acad. Sci. U.S.A. 103, 11160-11165. doi: $10.1073 /$ pnas. 0510834103

Napolitano, S., Matrone, N., Muddassir, A. L., Martini, G., Sorokin, A., De Falco, V., et al. (2019). Triple blockade of EGFR, MEK and PD-L1 has antitumor activity in colorectal cancer models with constitutive activation of MAPK signaling and PD-L1 overexpression. J. Exp. Clin. Cancer Res. 38:492. doi: 10.1186/s13046019-1497-0

Nguyen, A., Ho, L., Workenhe, S. T., Chen, L., Samson, J., Walsh, S. R., et al. (2018). HDACi delivery reprograms tumor-infiltrating myeloid cells to eliminate antigen-loss variants. Cell Rep. 24, 642-654. doi: 10.1016/j.celrep.2018.06.040

O’Connor, O. A., Falchi, L., Lue, J. K., Marchi, E., Kinahan, C., Sawas, A., et al. (2019). Oral 5-azacytidine and romidepsin exhibit marked activity in patients with PTCL: a multicenter phase 1 study. Blood 134, 1395-1405. doi: 10.1182/ blood.2019001285

Park, D., Park, H., Kim, Y., Kim, H., and Jeoung, D. (2014). HDAC3 acts as a negative regulator of angiogenesis. BMB Rep. 47, 227-232. doi: 10.5483/ bmbrep.2014.47.4.128

Pedini, F., De Luca, G., Felicetti, F., Puglisi, R., Boe, A., Arasi, M. B., et al. (2019). Joint action of miR-126 and MAPK/PI3K inhibitors against metastatic melanoma. Mol. Oncol. 13, 1836-1854. doi: 10.1002/1878-0261.12506

Qu, C., Gao, S., Shao, H., Zhang, W., Bo, H., Lu, X., et al. (2018). Identification of an HLA-A2-restricted CD147 epitope that can induce specific CTL cytotoxicity against drug resistant MCF-7/Adr cells. Oncol. Lett. 15, 6050-6056. doi: 10. 3892/ol.2018.8085

Rajan, A., Shi, H., and Xue, B. (2018). Class I and II histone deacetylase inhibitors differentially regulate thermogenic gene expression in brown adipocytes. Sci. Rep. 8:13072. doi: 10.1038/s41598-018-31560-w

Rajendran, P., Johnson, G., Li, L., Chen, Y. S., Dashwood, M., Nguyen, N., et al. (2019). Acetylation of CCAR2 establishes a BET/BRD9 acetyl switch in response to combined deacetylase and bromodomain inhibition. Cancer Res. 79, 918-927. doi: 10.1158/0008-5472.CAN-18-2003

Richard, G., Dalle, S., Monet, M. A., Ligier, M., Boespflug, A., Pommier, R. M., et al. (2016). ZEB1-mediated melanoma cell plasticity enhances resistance to MAPK inhibitors. EMBO Mol. Med. 8, 1143-1161. doi: 10.15252/emmm.201505971

Ridolfi, L., De Rosa, F., Petracci, E., Tanda, E. T., Marra, E., Pigozzo, J., et al. (2020). Anti-PD1 antibodies in patients aged $=75$ years with metastatic melanoma: a retrospective multicentre study. J. Geriatr. Oncol. 11, 515-522. doi: 10.1016/j. jgo.2019.12.012

Rizos, H., Menzies, A. M., Pupo, G. M., Carlino, M. S., Fung, C., Hyman, J., et al. (2014). BRAF inhibitor resistance mechanisms in metastatic melanoma: spectrum and clinical impact. Clin. Cancer Res. 20, 1965-1977.

Robert, C., Karaszewska, B., Schachter, J., Rutkowski, P., Mackiewicz, A., Stroiakovski, D., et al. (2015). Improved overall survival in melanoma with combined dabrafenib and trametinib. N. Engl. J. Med. 372, 30-39. doi: 10.1056/ NEJMoa1412690

Roesch, A., Vultur, A., Bogeski, I., Wang, H., Zimmermann, K. M., Speicher, D., et al. (2013). Overcoming intrinsic multidrug resistance in melanoma by blocking the mitochondrial respiratory chain of slow-cycling JARID1B(high) cells. Cancer Cell 23, 811-825. doi: 10.1016/j.ccr.2013.05.003

Roskoski, R. (2018). Targeting oncogenic Raf protein-serine/threonine kinases in human cancers. Pharmacol. Res. 135, 239-258. doi: 10.1016/j.phrs.2018. 08.013

Rossi, A., Roberto, M., Panebianco, M., Botticelli, A., Mazzuca, F., and Marchetti, P. (2019). Drug resistance of BRAF-mutant melanoma: review of up-to-date mechanisms of action and promising targeted agents. Eur. J. Pharmacol. 862:172621. doi: 10.1016/j.ejphar.2019.172621

Sahakian, E., Powers, J. J., Chen, J., Deng, S. L., Cheng, F., Distler, A., et al. (2015). Histone deacetylase 11: a novel epigenetic regulator of myeloid derived suppressor cell expansion and function. Mol. Immunol. 63, 579-585. doi: 10. 1016/j.molimm.2014.08.002

Seip, K., Fleten, K. G., Barkovskaya, A., Nygaard, V., Haugen, M. H., Engesaeter, B. O., et al. (2016). Fibroblast-induced switching to the mesenchymal-like 
phenotype and PI3K/mTOR signaling protects melanoma cells from BRAF inhibitors. Oncotarget 7, 19997-20015. doi: 10.18632/oncotarget.7671

Shi, H., Hong, A., Kong, X., Koya, R. C., Song, C., Moriceau, G., et al. (2014). A novel AKT1 mutant amplifies an adaptive melanoma response to BRAF inhibition. Cancer Discov. 4, 69-79. doi: 10.1158/2159-8290.CD-13-0279

Shinohara, H., Sugito, N., Kuranaga, Y., Heishima, K., Minami, Y., Naoe, T., et al. (2019). Potent antiproliferative effect of fatty-acid derivative AIC-47 on leukemic mice harboring BCR-ABL mutation. Cancer Sci. 110, 751-760. doi: $10.1111 /$ cas. 13913

Smith, M. P., Brunton, H., Rowling, E. J., Ferguson, J., Arozarena, I., Miskolczi, Z., et al. (2016). Inhibiting drivers of non-mutational drug tolerance is a salvage strategy for targeted melanoma therapy. Cancer Cell 29, 270-284. doi: 10.1016/ j.ccell.2016.02.003

Smith, M. P., Rana, S., Ferguson, J., Rowling, E. J., Flaherty, K. T., Wargo, J. A., et al. (2019). A PAX3/BRN2 rheostat controls the dynamics of BRAF mediated MITF regulation in MITF(high)/AXL(low) melanoma. Pigment Cell Melanoma Res. 32, 280-291. doi: 10.1111/pcmr.12741

Stone, M. L., Chiappinelli, K. B., Li, H., Murphy, L. M., Travers, M. E., Topper, M. J., et al. (2017). Epigenetic therapy activates type I interferon signaling in murine ovarian cancer to reduce immunosuppression and tumor burden. Proc. Natl. Acad. Sci. U.S.A. 114, E10981-E10990. doi: 10.1073/pnas.1712514114

Su, Y., Bintz, M., Yang, Y., Robert, L., Ng, A. H. C., Liu, V., et al. (2019). Phenotypic heterogeneity and evolution of melanoma cells associated with targeted therapy resistance. PLoS Comput. Biol. 15:e1007034. doi: 10.1371/journal.pcbi.1007034

Sun, T., Li, Y., Yang, W., Wu, H., Li, X., Huang, Y., et al. (2019). Histone deacetylase inhibition up-regulates MHC class I to facilitate cytotoxic T lymphocytemediated tumor cell killing in glioma cells. J. Cancer 10, 5638-5645. doi: 10. 7150/jca.34471

Tang, Z., Ding, S., Huang, H., Luo, P., Qing, B., Zhang, S., et al. (2017). HDAC1 triggers the proliferation and migration of breast cancer cells via upregulation of interleukin-8. Biol. Chem. 398, 1347-1356. doi: 10.1515/hsz-2017-0155

Ugurel, S., Schadendorf, D., Horny, K., Sucker, A., Schramm, S., Utikal, J., et al. (2020). Elevated baseline serum PD-1 or PD-L1 predicts poor outcome of PD-1 inhibition therapy in metastatic melanoma. Ann. Oncol. 31, 144-152. doi: 10.1016/j.annonc.2019.09.005

Vachtenheim, J., and Ondrusova, L. (2015). Microphthalmia-associated transcription factor expression levels in melanoma cells contribute to cell invasion and proliferation. Exp. Dermatol. 24, 481-484. doi: 10.1111/exd.12724

Van Allen, E. M., Wagle, N., Sucker, A., Treacy, D. J., Johannessen, C. M., Goetz, E. M., et al. (2014). The genetic landscape of clinical resistance to RAF inhibition in metastatic melanoma. Cancer Discov. 4, 94-109.

Venugopal, B., Baird, R., Kristeleit, R. S., Plummer, R., Cowan, R., Stewart, A., et al. (2013). A phase I study of quisinostat (JNJ-26481585), an oral hydroxamate histone deacetylase inhibitor with evidence of target modulation and antitumor activity, in patients with advanced solid tumors. Clin. Cancer Res. 19, 42624272. doi: 10.1158/1078-0432.CCR-13-0312

Villanueva, J., Vultur, A., Lee, J. T., Somasundaram, R., Fukunaga-Kalabis, M., Cipolla, A. K., et al. (2010). Acquired resistance to BRAF inhibitors mediated by a RAF kinase switch in melanoma can be overcome by cotargeting MEK and IGF-1R/PI3K. Cancer Cell 18, 683-695. doi: 10.1016/j.ccr.2010.11.023

Wang, H. Y., Wu, X. Y., Zhang, X., Yang, X. H., Long, Y. K., Feng, Y. F., et al. (2019). Prevalence of NRAS mutation, pd-ll expression and amplification, and overall survival analysis in 36 primary vaginal melanomas. Oncologist 25, e291-e301. doi: 10.1634/theoncologist.2019-0148

Wang, L., Leite de Oliveira, R., Huijberts, S., Bosdriesz, E., Pencheva, N., Brunen, D., et al. (2018). An acquired vulnerability of drug-resistant melanoma with therapeutic potential. Cell 173, 1413-1425.e14. doi: 10.1016/j.cell.2018.04.012
Welsh, S. J., Rizos, H., Scolyer, R. A., and Long, G. V. (2016). Resistance to combination BRAF and MEK inhibition in metastatic melanoma: Where to next? Eur. J. Cancer 62, 76-85. doi: 10.1016/j.ejca.2016.04.005

Woan, K. V., Lienlaf, M., Perez-Villaroel, P., Lee, C., Cheng, F., Knox, T., et al. (2015). Targeting histone deacetylase 6 mediates a dual anti-melanoma effect: enhanced antitumor immunity and impaired cell proliferation. Mol. Oncol. 9, 1447-1457. doi: 10.1016/j.molonc.2015.04.002

Wongjampa, W., Ekalaksananan, T., Chopjitt, P., Chuerduangphui, J., Kleebkaow, P., Patarapadungkit, N., et al. (2018). Suppression of miR-22, a tumor suppressor in cervical cancer, by human papillomavirus 16 E6 via a p53/miR22/HDAC6 pathway. PLoS One 13:e0206644. doi: 10.1371/journal.pone. 0206644

Woo, P. Y. M., Lam, T. C., Pu, J. K. S., Li, L. F., Leung, R. C. Y., Ho, J. M. K., et al. (2019). Regression of BRAF (V600E) mutant adult glioblastoma after primary combined BRAF-MEK inhibitor targeted therapy: a report of two cases. Oncotarget 10, 3818-3826.

Wu, J. Y., Xiang, S., Zhang, M., Fang, B., Huang, H., Kwon, O. K., et al. (2018). Histone deacetylase 6 (HDAC6) deacetylates extracellular signal-regulated kinase 1 (ERK1) and thereby stimulates ERK1 activity. J. Biol. Chem. 293, 1976-1993. doi: 10.1074/jbc.M117.795955

Xiao, J., Egger, M. E., McMasters, K. M., and Hao, H. (2018). Differential expression of ABCB5 in BRAF inhibitor-resistant melanoma cell lines. BMC Cancer 18:675. doi: 10.1186/s12885-018-4583-3

Xiong, K., Zhang, H., Du, Y., Tian, J., and Ding, S. (2019). Identification of HDAC9 as a viable therapeutic target for the treatment of gastric cancer. Exp. Mol. Med. 51, 1-15. doi: 10.1038/s12276-019-0301-8

Xue, Y., Lian, W., Zhi, J., Yang, W., Li, Q., Guo, X., et al. (2019). HDAC5-mediated deacetylation and nuclear localisation of SOX9 is critical for tamoxifen resistance in breast cancer. Br. J. Cancer 121, 1039-1049. doi: 10.1038/s41416019-0625-0

Yang, Z., Qi, Y., Lai, N., Zhang, J., Chen, Z., Liu, M., et al. (2018). Notch1 signaling in melanoma cells promoted tumor-induced immunosuppression via upregulation of TGF-beta1. J. Exp. Clin. Cancer Res. 37:1. doi: 10.1186/s13046017-0664-4

Yarchoan, M., Mohan, A. A., Dennison, L., Vithayathil, T., Ruggieri, A., Lesinski, G. B., et al. (2019). MEK inhibition suppresses B regulatory cells and augments anti-tumor immunity. PLoS One 14:e0224600. doi: 10.1371/journal. pone. 0224600

Ye, M., Fang, Z., Gu, H., Song, R., Ye, J., Li, H., et al. (2017). Histone deacetylase 5 promotes the migration and invasion of hepatocellular carcinoma via increasing the transcription of hypoxia-inducible factor-1alpha under hypoxia condition. Tumour Biol. 39:1010428317705034. doi: 10.1177/101042831770 5034

Zhu, Q., Yu, L., Qin, Z., Chen, L., Hu, H., Zheng, X., et al. (2019). Regulation of OCT2 transcriptional repression by histone acetylation in renal cell carcinoma. Epigenetics 14, 791-803. doi: 10.1080/15592294.2019.1615354

Conflict of Interest: The authors declare that the research was conducted in the absence of any commercial or financial relationships that could be construed as a potential conflict of interest.

Copyright (c) 2020 Yeon, Kim, Jung and Jeoung. This is an open-access article distributed under the terms of the Creative Commons Attribution License (CC BY). The use, distribution or reproduction in other forums is permitted, provided the original author(s) and the copyright owner(s) are credited and that the original publication in this journal is cited, in accordance with accepted academic practice. No use, distribution or reproduction is permitted which does not comply with these terms. 